\title{
Do atmospheric aerosols form glasses?
}

\author{
B. Zobrist ${ }^{1,2}$, C. Marcolli ${ }^{1}$, D. A. Pedernera ${ }^{2}$, and T. Koop ${ }^{2}$ \\ ${ }^{1}$ Institute for Atmospheric and Climate Science, ETH Zurich, Zurich, Switzerland \\ ${ }^{2}$ Department of Chemistry, Bielefeld University, Bielefeld, Germany
}

Received: 15 April 2008 - Published in Atmos. Chem. Phys. Discuss.: 20 May 2008

Revised: 21 July 2008 - Accepted: 12 August 2008 - Published: 3 September 2008

\begin{abstract}
A new process is presented by which water soluble organics might influence ice nucleation, ice growth, chemical reactions and water uptake of aerosols in the upper troposphere: the formation of glassy aerosol particles. Glasses are disordered amorphous (non-crystalline) solids that form when a liquid is cooled without crystallization until the viscosity increases exponentially and molecular diffusion practically ceases. The glass transition temperatures, $T_{\mathrm{g}}$, homogeneous ice nucleation temperatures, $T_{\mathrm{hom}}$, and ice melting temperatures, $T_{\mathrm{m}}$, of various aqueous inorganic, organic and multi-component solutions are investigated with a differential scanning calorimeter. The investigated solutes are: various polyols, glucose, raffinose, levoglucosan, an aromatic compound, sulfuric acid, ammonium bisulfate and mixtures of dicarboxylic acids (M5), of dicarboxylic acids and ammonium sulfate (M5AS), of two polyols, of glucose and ammonium nitrate, and of raffinose and M5AS. The results indicate that aqueous solutions of the investigated inorganic solutes show $T_{\mathrm{g}}$ values that are too low to be of atmospheric importance. In contrast, aqueous organic and multicomponent solutions readily form glasses at low but atmospherically relevant temperatures $(\leq 230 \mathrm{~K})$. To apply the laboratory data to the atmospheric situation, the measured phase transition temperatures were transformed from a concentration to a water activity scale by extrapolating water activities determined between $252 \mathrm{~K}$ and $313 \mathrm{~K}$ to lower temperatures. The obtained state diagrams reveal that the higher the molar mass of the aqueous organic or multi-component solutes, the higher $T_{\mathrm{g}}$ of their respective solutions at a given water activity. To a lesser extent, $T_{\mathrm{g}}$ also depends on the hydrophilicity of the organic solutes. Therefore, aerosol particles containing larger $\left(\gtrsim 150 \mathrm{~g} \mathrm{~mol}^{-1}\right)$ and more hydrophobic organic molecules are more likely to form glasses at inter-
\end{abstract}

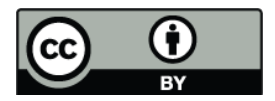

Correspondence to: T. Koop (thomas.koop@uni-bielefeld.de) mediate to high relative humidities in the upper troposphere. Our results suggest that the water uptake of aerosols, heterogeneous chemical reactions in aerosol particles, as well as ice nucleation and ice crystal growth can be significantly impeded or even completely inhibited in organic-enriched aerosols at upper tropospheric temperatures with implications for cirrus cloud formation and upper tropospheric relative humidity.

\section{Introduction}

Depending on their concentration and composition, aerosols affect different atmospheric properties and processes, such as atmospheric chemistry and Earth's radiative budget. For example, the aerosol climate forcing can be divided into a direct and an indirect aerosol effect (e.g. Hansen et al., 1998; Haywood and Boucher, 2000; Lohmann and Feichter, 2005). The direct aerosol effect is due to scattering and absorption of sunlight by aerosols, and it depends on aerosol properties such as physical state, size, absorption cross section and chemical composition (e.g. Haywood and Boucher, 2000). Depending on ambient relative humidity, aerosol particles grow or shrink by taking up or releasing water vapor thus enhancing or reducing the scattering intensity of the aerosol (Carrico et al., 2003; Quinn et al., 2005; Baynard et al., 2006). Aerosols exert also an indirect effect by acting as cloud condensation nuclei for liquid clouds or as ice nuclei for ice clouds, thereby affecting the initial cloud particle number concentration, cloud lifetime and albedo (Albrecht, 1989; Lohmann and Feichter, 2005). According to the recent Intergovernmental Panel on Climate Change report (IPCC, 2007), the direct and indirect aerosol effects (including only liquid clouds) exert radiative forcings of -0.5 and $-0.7 \mathrm{~W} \mathrm{~m}^{-2}$, respectively, but exhibit only a low to medium level of scientific understanding.

Published by Copernicus Publications on behalf of the European Geosciences Union. 
The atmospheric aerosol is a complex mixture of various inorganic and organic components. The organic fraction can represent $50 \%$ or more of the total aerosol mass depending on geographical location and/or altitude (e.g. Novakov et al., 1997; Middlebrook et al., 1998; Kanakidou et al., 2005; Murphy et al., 2006), but its composition in terms of chemical structures of individual molecules remains unidentified to a large extent (Saxena and Hildemann, 1996; Kanakidou et al., 2005). The water soluble organic fraction contributes substantially to the total organic aerosol and typically contains mono-, di- and polycarboxylic acids, polyols, dialkyl ketones, polyphenols, aromatic aldehydes and acids, sugars, anhydrosugars and other functional groups (Rogge et al., 1993; Kanakidou et al., 2005; Decesari et al., 2006).

Aerosol particles in the atmosphere may occur as solid or liquid particles or as a mixture of both depending on their composition and ambient conditions (e.g. Martin, 2000; Colberg et al., 2003; Marcolli et al., 2004). The organic fraction, however, tends to remain liquid instead of crystallizing as the temperature is decreased and, thus, organic aerosol particles may form highly viscous liquids (Marcolli et al., 2004). When the viscosity of such a liquid reaches a value in the order of $10^{12} \mathrm{Pas}$, the molecular motion becomes so slow, that the sample vitrifies within timescales of seconds to minutes at the glass transition temperature $T_{\mathrm{g}}$ (Debenedetti and Stillinger, 2001). Glasses are amorphous substances that behave mechanically like solids (Debenedetti, 1996). The ability to form a glass depends strongly on the chemical and physical properties of a given substance and its mixing state (Angell, 1995, 2002). Glasses are ubiquitous in nature (Angell, 1995) and are widely applied in bioengineering (Langer and Vacanti, 1993), food technology (Slade and Levine, 1994), pharmaceutical industries (Kerč and Srčič, 1995; Craig et al., 1999; Hancock and Zografi, 1997) or cryobiology (Pegg and Karow, 1987; Angell, 2002).

If aerosol particles were present as glasses, this would influence several physical and chemical processes in the atmosphere significantly: Water uptake from the gas phase would be drastically impeded or even completely inhibited in glassy aerosols, thus reducing the direct aerosol effect. Similarly, glass formation would affect the ice nucleation efficiency of aerosol particles. Peter et al. (2006) recently suggested that a suppressed ice nucleation might be a possible explanation of the observed high supersaturations with respect to ice in recent field experiments (Jensen et al., 2005). Furthermore, if aged aerosols become more and more viscous due to polymerization reactions (e.g. Kalberer et al., 2004; Denkenberger et al., 2007) they might turn more easily into glasses and further aerosol processing could be ceased.

In this study, the potential of atmospheric aerosols to form glasses will be explored by investigating the glass transition temperatures of atmospherically relevant aqueous solutions. The paper is structured in the following way: Sect. 2 compares the thermodynamics of glass and crystallization/melting phase transitions. Section 3 exemplifies the use of differential scanning calorimetry to observe such phase transitions in aqueous solutions. Sections 4 and 5 compare the dependence of glass transition temperatures of aqueous solutions on their concentration and water activity. Sections 6 to 8 show results of glass transition temperature measurements of various aqueous organic, inorganic and multicomponent solutions of atmospheric relevance. Finally, in Sect. 9, the potential effects of glassy aerosols on atmospheric processes are discussed.

\section{Physical background of glass transition}

Figure 1a depicts schematically the enthalpy $H$ and the entropy $S$ change as a function of temperature for a liquid-tosolid phase transition and a glass transition. Cooling a stable liquid results normally in a decrease in both $H$ and $S$ (green line). If crystallization occurs without supercooling at the equilibrium melting point $T_{\mathrm{m}}$ (vertical blue line), this causes an abrupt decrease in $H$ and $S$, which is indicative of a firstorder phase transition (Atkins, 1996). Cooling the crystal to even lower temperatures further decreases $H$ and $S$ in a continuous way (slanted blue line). Upon warming the system follows the same path since both $H$ and $S$ are thermodynamic state functions.

The behavior described above is, however, an idealized case, because most liquids do not show a completely reversible behavior at $T_{\mathrm{m}}$; instead they usually exhibit supercooling below $T_{\mathrm{m}}$ as crystallization is kinetically hindered and requires a nucleation process. In this case, $H$ and $S$ decrease continuously even below $T_{\mathrm{m}}$ (green line to the left of $T_{\mathrm{m}}$ ). In such a supercooled (metastable) liquid nucleation can occur at any given moment, in which case $H$ and $S$ would drop abruptly to their crystal values at the nucleation temperature. The viscosity of the liquid increases upon cooling, slowing down molecular motion, which in turn may inhibit nucleation and/or crystal growth. At even lower temperatures, molecular motion becomes so slow that on the experimental timescale the molecules cannot equilibrate to the lowest energy state of the liquid (Debenedetti, 1996; Debenedetti and Stillinger, 2001).

This kinetic phenomenon is called vitrification or glass formation and the corresponding temperature is termed the glass transition temperature, $T_{\mathrm{g}}$. Below $T_{\mathrm{g}}$, the substance is a glass, i.e. a non-crystalline amorphous state that behaves mechanically like a solid (Debenedetti and Stillinger, 2001). Because translational and reorientational degrees of freedom practically are frozen on experimental timescales below $T_{\mathrm{g}}$, $H$ and $S$ in the glassy state decrease upon cooling with a slope that is similar to that of the crystal (red line, Angell, 2008). The change in slope of $H$ and $S$ at $T_{\mathrm{g}}$ is indicative of the glass transition. During the glass transition neither a release of latent enthalpy nor a discontinuous change in the ordering of the molecules occurs, thus, glass formation is not easily observed by many experimental techniques. One 
standard technique that is very well suited for investigations of both crystal nucleation and glass formation is Differential Scanning Calorimetry (Folmer and Franzen, 2003). This is, because this technique is sensitive to the isobaric heat capacity of the sample, $c_{\mathrm{p}}=(\partial H / \partial T)_{\mathrm{p}}$, i.e. the slope of $H$ in Fig. 1a.

Panels (b) and (c) of Fig. 1 show the temperature dependence of $c_{\mathrm{p}}$ for a first-order liquid-to-solid phase transition and a glass transition, respectively. Also included as the dashed grey curves are the signals that are typically observed in Differential Scanning Calorimetry (DSC) experiments for such phase transitions. Figure $1 \mathrm{~b}$ shows that the crystal exhibits a smaller $c_{\mathrm{p}}$ value than the liquid. Within a limited temperature range around $T_{\mathrm{m}}$ one can assume $c_{\mathrm{p}}$ of both phases to be approximately independent of temperature. Upon warming latent heat is absorbed by the crystal at $T_{\mathrm{m}}$ without any increase in temperature, i.e. $H$ changes instantaneously and, hence, $c_{\mathrm{p}}$ nominally becomes infinite at $T_{\mathrm{m}}$ (indicated by the vertical blue and green arrows). However, because of the inherent thermal lag within the DSC apparatus, the DSC thermogram displays a broadened peak, with the integrated peak area of the grey dashed line amounting the total melting enthalpy of the sample.

Figure 1c shows the behavior of $c_{\mathrm{p}}$ upon heating a glass. Here, $c_{\mathrm{p}}$ changes from the smaller value of the glass to the higher value of the (supercooled) liquid at $T_{\mathrm{g}}$. The step-like DSC signal in panel (c) closely follows the change in $c_{\mathrm{p}}$. In the following section, we will show several examples of DSC experiments in which crystallization and melting processes as well as glass transitions occurred.

\section{Competition between glass formation and ice crystal- lization in aqueous solutions}

Glass formation is observed in many different systems such as minerals, metals, polymers, and also in aqueous solutions (e.g. Angell, 1995; Debenedetti and Stillinger, 2001; Angell, 2002). Even pure water can vitrify, however, only when hyperquenching small water samples at extremely large cooling rates of $\sim 10^{5} \mathrm{~K} \mathrm{~s}^{-1}$ (Kohl et al., 2005). At moderate cooling rates $\left(\leq 20 \mathrm{~K} \mathrm{~min}^{-1}\right)$ ice nucleates readily in water and dilute aqueous solutions before glass formation occurs. On the other hand, at very high solute concentrations glass formation is observed frequently even when cooling rates are moderate. In the following section, the different processes that occur in aqueous solutions of varying solute concentration are discussed using aqueous glucose solutions as a model system.

On the left-hand side of Fig. 2 three typical DSC thermograms are shown. The experiments were performed with emulsified samples, i.e. small micrometer-sized aqueous droplets in an inert oil matrix (see Appendix A1 for experimental details). The small arrowheads in panels (a)-(c) show the course of the experimental runs. The capital let-
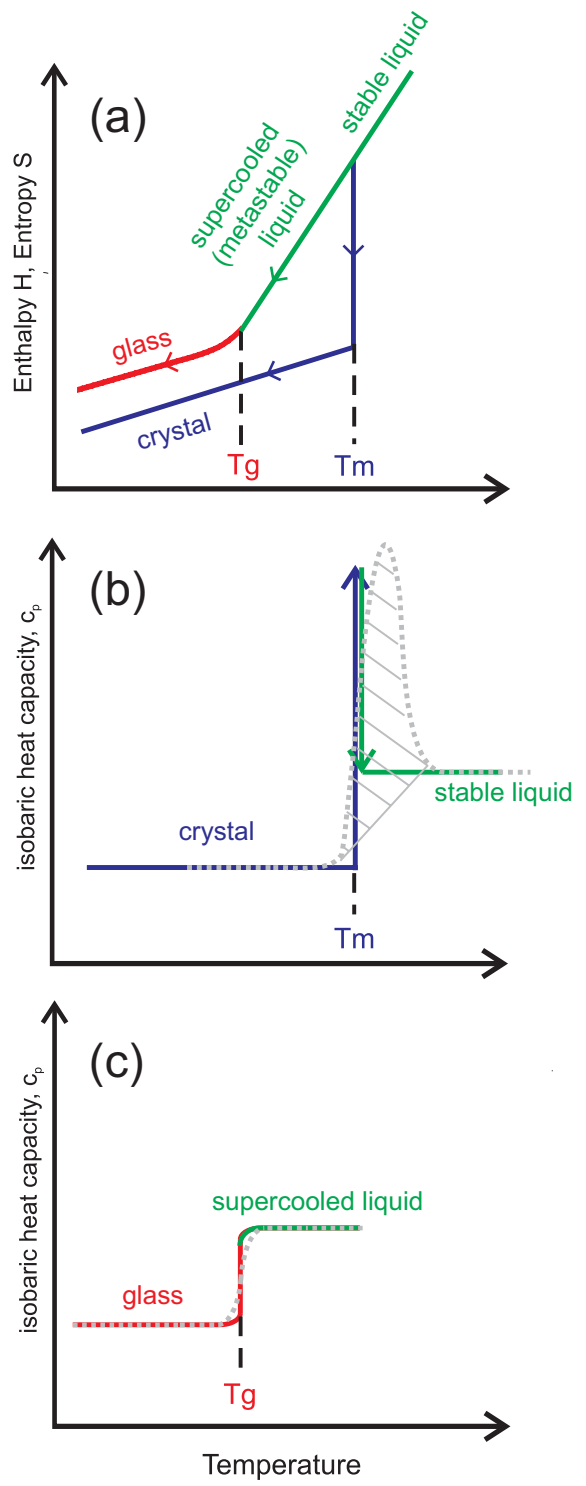

Fig. 1. Thermodynamic representation of a crystallization/melting (first-order phase change) and a glass transition. (a): Enthalpy and entropy change during the phase transitions; (b) and (c) isobaric heat capacity for a first-order phase change and a glass transition. This figure is adapted from Debenedetti and Stillinger (2001) and from Folmer and Franzen (2003).

ters indicate points that are of special interest (see discussion below). Panels (d)-(f) on the right-hand side depict the binary glucose/water state diagrams as a function of the glucose weight fraction. In these panels, the black lines represent the ice melting point curve, $T_{\mathrm{m}}$, the homogeneous ice nucleation curve, $T_{\mathrm{hom}}$, and the glass transition curve, $T_{\mathrm{g}}$ (All curves are based on experimental data points, given as symbols, from this and previous studies). Water is supersaturated in the area between $T_{\mathrm{m}}$ and $T_{\mathrm{hom}}$, but can persist as a metastable liquid upon cooling because ice formation in that 

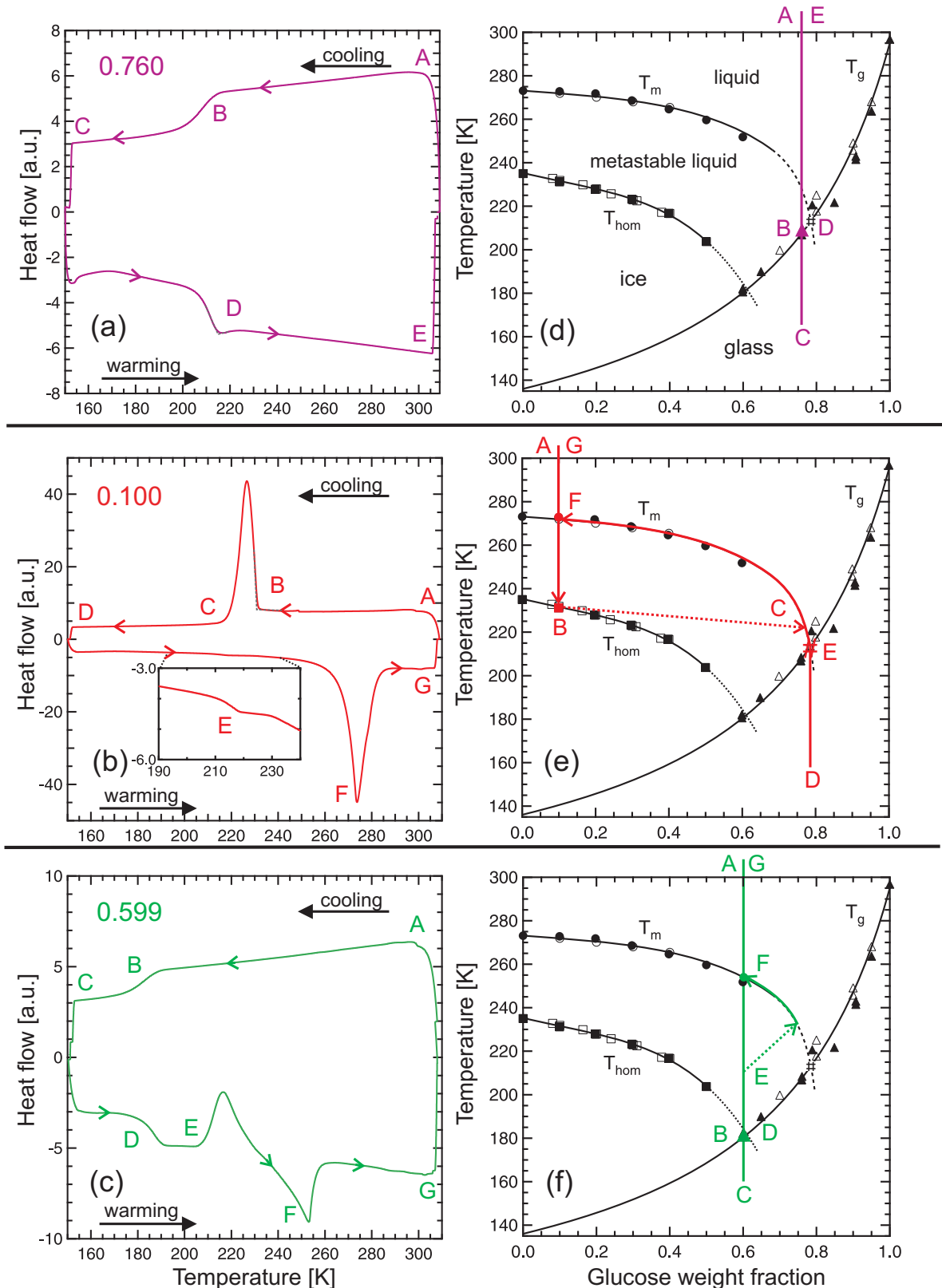

Fig. 2. DSC thermograms, (a)-(c), and state diagrams, (d)-(f), of aqueous glucose solutions. The upper, middle and lower panels (separated by black lines) show the measurements for aqueous solutions with glucose weight fractions of $0.760,0.10$ and 0.599 , respectively. The experiments in (a)-(c) show cooling/heating cycles from $\sim 308 \mathrm{~K}$ to $\sim 153 \mathrm{~K}$ with $10 \mathrm{Kmin}^{-1}$. (d)-(f): Filled symbols are data from this study, open symbols from literature: circles (Rasmussen and MacKenzie, 1972), squares (Rasmussen and MacKenzie, 1972; Miyata and Kanno, 2005) and triangles (Roos, 1993; Seo et al., 2004). The hash denotes the glass transition temperature of the freeze concentrated solution. The ice melting curve, $T_{\mathrm{m}}$, is from Young (1957), and it is extrapolated to lower temperatures (dashed part) so that it intersects the glass transition curve at the measured glass transition temperature of the freeze concentrated solution (hash). The homogeneous freezing curve, $T_{\text {hom }}$, is a polynomial fit through all data points and the dotted part is an extrapolation to lower temperatures. The glass transition curve is obtained through a Gordon-Taylor fit (see also Sect. 4). The colored curves depict the course of the DSC experiments linked to the panel on the left side, e.g. (a) is linked with (d). The solid lines are based on the DSC measurements, while the dotted lines are idealized trajectories during the crystallization process when no phase equilibrium exists within the samples. The capital letters in the panels indicate points that are of special interest. 
region is kinetically hindered in small droplets. Note, that $T_{\mathrm{m}}$ depicts the equilibrium line of glucose solutions and hexagonal ice. However, metastable cubic ice might also form implying a slightly lower ice-liquid equilibrium curve, which might also be applicable in some experiments (see Murray, 2008b). Since we cannot determine cubic ice formation in our experiments and due to the lack of data on the exact equilibrium lines of cubic ice, we refer to the properties of hexagonal ice in our discussion. However, this does not restrict any statement in the conclusions. The colored lines and capital letters refer to the thermograms on the left-hand side, which we now discuss individually.

Figure $2 \mathrm{a}$ shows an experimental run of a concentrated glucose solution with a solute weight fraction, $w_{2}$, of 0.760 . The sample is cooled from initially $308 \mathrm{~K}$ (point A) down to $153 \mathrm{~K}$ (point C). At around $210 \mathrm{~K}$ a smooth S-shaped step is observed (point B). Reheating the sample from point $\mathrm{C}$ to point $\mathrm{E}$ again results in a smooth step in the heat flow signal at a similar temperature (point D). The pathway A-E is also overlayed onto the state diagram in panel (d) as the colored line. Throughout the entire experiment the concentration of the solution remains constant. From this analysis we see that the colored line crosses the $T_{\mathrm{g}}$ curve at $\sim 210 \mathrm{~K}$, indicating that the observed steps in the thermograms are due to glass formation (point B) and the reverse glass-to-liquid transition (point D).

Figure $2 \mathrm{~b}$ shows an experiment of a dilute glucose solution with $w_{2}=0.100$. When the sample is cooled from $308 \mathrm{~K}$ (point A) to $153 \mathrm{~K}$ (point $\mathrm{D}$ ), a large exothermic signal appears at $\sim 230 \mathrm{~K}$ (point $\mathrm{B}$ ), due to homogeneous ice nucleation and growth in the aqueous droplets. The solute is expelled from the growing ice crystals resulting in the formation of a highly concentrated glucose solution. This is indicated in panel (e) by the dotted arrow connecting points $B$ and C. Upon further cooling, the concentration of the remaining solution follows the $T_{\mathrm{m}}$ curve, thereby further increasing in concentration, until it vitrifies at the point $\mathrm{E}$ where the $T_{\mathrm{m}}$ and $T_{\mathrm{g}}$ curves meet. The glass transition is not observable during the cooling cycle in panel (b) because it is hidden below the ice nucleation peak. Provided that the ice crystals cannot grow further in the glass, the concentration of the glassy solution remains constant upon further cooling (vertical line towards point D in panel e). During the heating cycle a small glass transition step of the glucose solution is observed (see point $E$ in the enlarged inlet of panel b). This point is termed $T_{\mathrm{g}}^{\prime}$ or "the glass transition temperature of the freeze concentrated solution", which is marked in panel (e) with a red hash at point E. Upon further heating, the solution concentration follows the $T_{\mathrm{m}}$ curve and the ice continuously melts until at point $F$ the entire sample is again liquid.

Figure 2c depicts an experiment of a glucose solution at intermediate concentration with $w_{2}=0.599$. Upon cooling from $308 \mathrm{~K}$ (point $\mathrm{A}$ ) to $153 \mathrm{~K}$ (point $\mathrm{C}$ ) a glass transition is observed at $\sim 180 \mathrm{~K}$ (point $\mathrm{B}$ ), see panel (f) for comparison. In the heating cycle, the glass-to-liquid transition is again observed at $\sim 180 \mathrm{~K}$. Then an additional exothermic peak appears at $\sim 210 \mathrm{~K}$ (point $\mathrm{E}$ ). This signal can be attributed to ice crystallization in the sample, which leads to an increase of the glucose solution concentration until the $T_{\mathrm{m}}$ curve is reached (dotted arrow in panel $\mathrm{f}$ ). There the ice starts to melt upon heating until it is completely melted at $\sim 255 \mathrm{~K}$ (endothermic peak in panel c (point $\mathrm{F}$ ), see also panel (f) for comparison). At this point the solution reaches its initial weight fraction of 0.599. The experiment shown in Fig. 2c imposes the question of why ice formation did not occur during the cooling cycle but only upon warming. It seems reasonable that ice germs larger than the critical size may have nucleated during cooling when the sample crossed the extrapolated $T_{\text {hom }}$ curve just before it vitrified at point B. However, the very high viscosity of the sample inhibited the ice crystal growth. No signal is observed in the thermogram, because the release of latent heat due to the formation of critical germs is much too small to be detected by the DSC. Upon heating, the solution viscosity became low enough at about $30 \mathrm{~K}$ above $T_{\mathrm{g}}$ so that the ice germs in the droplets could grow to macroscopic crystals, resulting in the exothermic peak at point $\mathrm{E}$.

To summarize this section, three principal cases of glass formation in aqueous solutions can be distinguished in Fig. 2. Firstly, the aqueous solution is so concentrated that ice does not crystallize and a glass formation is observed at $T_{\mathrm{g}}$. Secondly, in dilute solutions ice crystallizes homogeneously and glass formation in the freeze concentrated solution occurs at $T_{\mathrm{g}}^{\prime}$ upon cooling. $T_{\mathrm{g}}^{\prime}$ is a unique point in the state diagram of each solute, defined as the intersection between the $T_{\mathrm{g}}$ and $T_{\mathrm{m}}$ curves. Thirdly, at intermediate concentrations, some solutions vitrify upon cooling and do not form ice until temperatures typically $10-30 \mathrm{~K}$ above $T_{\mathrm{g}}$ are reached.

\section{$4 \mathbf{T}_{\mathrm{g}}$ in aqueous solutions - organic versus inorganic so- lutes}

Figure 3 shows $T_{\mathrm{g}}$ as a function of the solute weight fraction for selected organic and inorganic solutes. The displayed organic solutes raffinose $\left(\mathrm{C}_{18} \mathrm{O}_{16} \mathrm{H}_{32}\right)$, glucose $\left(\mathrm{C}_{6} \mathrm{O}_{6} \mathrm{H}_{12}\right)$ and levoglucosan $\left(\mathrm{C}_{6} \mathrm{O}_{5} \mathrm{H}_{10}\right)$ represent constituents of a typical biomass burning aerosol (Decesari et al., 2006) and the inorganic solutes belong to the most frequently occurring inorganic substances in atmospheric aerosol particles. The triangles and squares represent experimental data from this and reference studies, respectively, and the colored curves are fits to the data according to Eq. 1 (see discussion below).

All solutions exhibit a strong dependence of $T_{\mathrm{g}}$ on the solute weight fraction, $w_{2}$, with larger $w_{2}$ values leading to higher $T_{\mathrm{g}}$. All curves have the $T_{\mathrm{g}}$ value of pure water in common ( $136 \mathrm{~K}$ at $w_{2}=0$, see black triangle in Fig. 3), but show different slopes with increasing solute weight fraction. The increase of $T_{\mathrm{g}}$ with increasing $w_{2}$ is strongest for raffinose and weakest for $\mathrm{NH}_{4} \mathrm{HSO}_{4}$. It is noteworthy that 


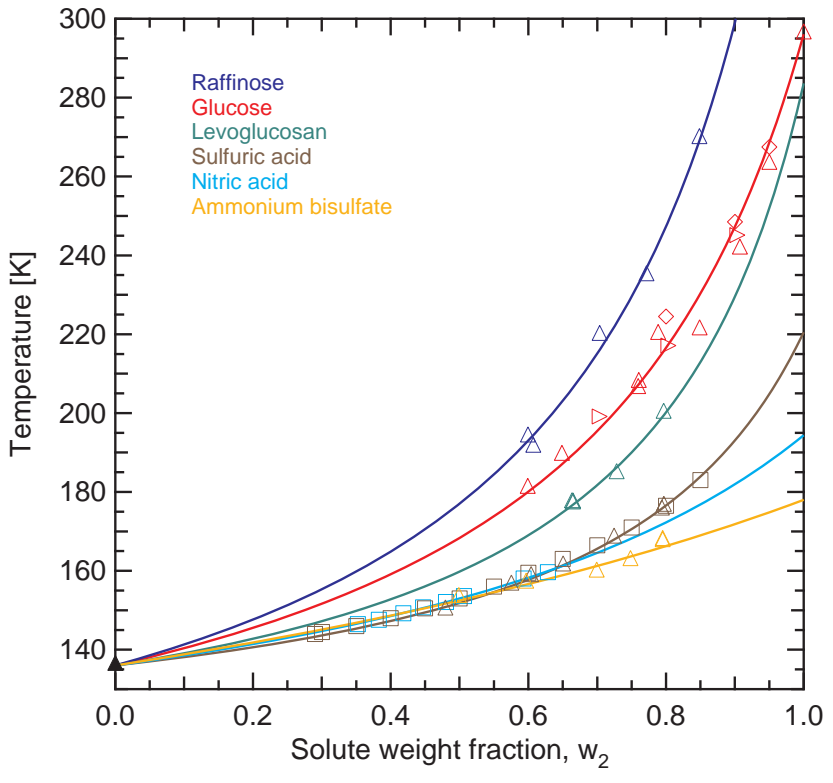

Fig. 3. Glass temperatures as a function of the solute weight fraction for six organic and inorganic solutes. The open triangles are measurements from this study. Brown squares, blue squares, red diamonds and red right pointed triangles are data from Kanno and Itoi (1984), Satoh and Kanno (1982), Seo et al. (2004) and Roos (1993), respectively. The filled black triangle shows the glass temperature of pure water, which has a value of 136 K. (e.g. Johari et al., 1987; Kohl et al., 2005). The solid curves are calculated according to Eq. 1.

the organic solutes exhibit higher $T_{\mathrm{g}}$ values than the inorganic ones and that for organic solutes $T_{\mathrm{g}}$ at a given concentration is the higher, the larger the molar mass of the solute. Limitations exist for the concentration range over which glass formation can be determined experimentally when using moderate cooling rates, in agreement with our discussion of Fig. 2 above. For example, at low solute concentrations, $T_{\mathrm{g}}$ can be determined in sulfuric acid solutions only when $w_{2}$ exceeds a value of $\sim 0.3$, whereas aqueous glucose solution vitrify when $w_{2}$ exceeds $\sim 0.6$. At lower concentrations, ice nucleates homogeneously in the samples (see, e.g. Fig. 2b/e) although glasses could form if the samples were hyperquenched. Similar limitations exist when $w_{2}$ reaches values close to one, because the solute itself often crystallizes under such highly supersaturated conditions.

For various purposes it is desirable to have an appropriate description of $T_{\mathrm{g}}$ over the entire concentration range $0 \leq w_{2} \leq 1$. Indeed, Gordon and Taylor (1952) have developed an empirical formulation for $T_{\mathrm{g}}$ based on experimental data of binary polymer blends. This so-called GordonTaylor equation has been widely applied in polymer research (Koleske and Lundberg, 1969) and also to aqueous solutions of carbohydrates in food science (e.g. Roos, 1993). In aqueous solutions, the glass transition temperature at a specific solute weight fraction, $T_{\mathrm{g}}\left(w_{2}\right)$, can be expressed according to the Gordon-Taylor equation as (Gordon and Taylor, 1952; Katkov and Levine, 2004):

$T_{\mathrm{g}}\left(w_{2}\right)=\frac{w_{1} T_{\mathrm{g} 1}+\frac{1}{k} w_{2} T_{\mathrm{g} 2}}{w_{1}+\frac{1}{k} w_{2}}$,

where $w_{1}$ and $w_{2}$ are the weight fractions of water and of the solute, $T_{\mathrm{g} 1}$ and $T_{\mathrm{g} 2}$ are the glass transition temperatures of pure water and of the pure solute, and $k$ is a solute specific constant. In this study, we use a value of $136 \mathrm{~K}$ for $T_{\mathrm{g} 1}$ (Johari et al., 1987; Kohl et al., 2005). The colored lines in Fig. 3 are fits to the experimental data using Eq. (1). These fits yield values for $T_{\mathrm{g} 2}$ and $k$ as listed in Table A3 in Appendix A3 together with a sensitivity analysis of the fit parameters.

\section{Concentration versus water activity dependence of $\mathbf{T}_{\mathrm{m}}$ and $\mathbf{T}_{\mathrm{g}}$}

In the atmosphere, the concentration of an aqueous aerosol particle is determined by the ambient relative humidity, RH. Therefore, state diagrams in terms of the solute weight fraction as those shown in Figs. 2 and 3 have only limited applications for atmospheric considerations. A much better way is to show data in terms of temperature versus water activity, $a_{\mathrm{w}}$, because RH is equal to $a_{\mathrm{w}}$ of aerosol particles that are in equilibrium with the ambient relative humidity and for which the Kelvin effect is negligible.

This approach is shown in Fig. 4 for aqueous glucose and sulfuric acid solutions. In addition to the $T_{\mathrm{g}}$ curves, the ice melting point curves $\left(T_{\mathrm{m}}\right)$ are also shown. In panel (a) both substances show a decrease in $T_{\mathrm{m}}$ with increasing solute content, but a very different dependence on $w_{2}$. The glass transition temperatures increase with decreasing water content with glucose exhibiting higher $T_{\mathrm{g}}$ values than $\mathrm{H}_{2} \mathrm{SO}_{4}$ at similar concentrations. In panel (b), the same data are shown as a function of the water activity. Now the $T_{\mathrm{m}}$ curves of both solutes collapse onto a single line because the water activity of any aqueous solution in equilibrium with ice is the same independently of the nature of the solute (Koop, 2002). The shape of the two $T_{\mathrm{g}}$ curves is also modified. Both curves start at $T_{\mathrm{g} 1}=136 \mathrm{~K}$ and end at the solute specific $T_{\mathrm{g} 2}$ value. However, the glass transition curve in $\mathrm{H}_{2} \mathrm{SO}_{4}$ solutions does not exceed temperatures of $160 \mathrm{~K}$ for the most part of the $a_{\mathrm{w}}$-range. Only at $a_{\mathrm{w}} \lesssim 0.05, T_{\mathrm{g}}$ increases almost vertically towards $T_{\mathrm{g} 2}$. In contrast, $T_{\mathrm{g}}$ in glucose solutions increases considerably already at high water activities. The difference in $T_{\mathrm{g}}$ between the two solutes is strongly enhanced when compared to panel (a) because of the different $w_{2} \leftrightarrow a_{\mathrm{w}}$ dependence of the two solutes.

$\mathrm{A} \mathrm{H}_{2} \mathrm{SO}_{4}$ solution with a solute weight fraction of $w_{2}=0.6$ exhibits a water activity of only 0.05 , whereas a similarly concentrated glucose solution exhibits a water activity of $\sim 0.8$. The above weight fraction corresponds to a solute 

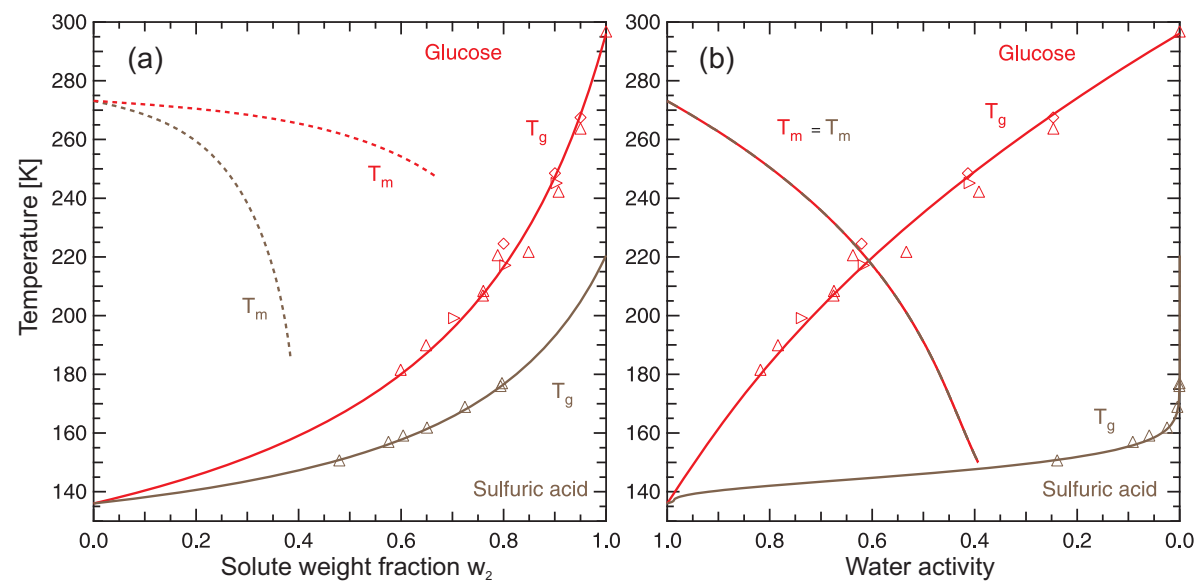

Fig. 4. Glass and ice melting temperatures of sulfuric acid and glucose as a function of the solute weight fraction, (a) and as a function of the water activity of the solution, (b). (a): Brown and red dashed lines: Ice melting temperatures of $\mathrm{H}_{2} \mathrm{SO}_{4}(\mathrm{Gable}$ et al., 1950) and glucose (Young, 1957); Brown and red symbols as in Fig. 3; Brown and red solid lines: Glass curves calculated according to Eq. 1. (b): Brown-red patterned line: Ice melting temperatures of $\mathrm{H}_{2} \mathrm{SO}_{4}$ and glucose according to Koop et al. (2000); Red symbols and red solid line: Glucose data of panel (a) converted from the concentration to the water activity scale using Eq. (A2). Brown triangles and brown solid line: $T_{\mathrm{g}}$ of $\mathrm{H}_{2} \mathrm{SO}_{4}$ as a function of $a_{\mathrm{W}}\left(w_{2}, T\right)$ calculated with the AIM-model by Clegg et al. (1998). For $T<180 \mathrm{~K}$ we assumed that $a_{\mathrm{W}}\left(w_{2}, T\right)=a_{\mathrm{W}}\left(w_{2}, T=180 \mathrm{~K}\right)$.

mole fraction of 0.355 (assuming that sulfuric acid dissociates to $\mathrm{H}^{+}$and $\mathrm{HSO}_{4}^{-}$) and a water activity of 0.05 at $T_{\mathrm{g}}$. A glucose solution with the same mole fraction exhibits a water activity of 0.532 at $T_{\mathrm{g}}$. This differing behavior can be understood by considering that $\mathrm{H}_{2} \mathrm{SO}_{4}$ (like other inorganic salts and acids) dissociates into charged ions, which strongly affect water activity even at smaller concentrations. In contrast, glucose and other non-dissociating water soluble organics interact with water mainly through hydrogen bonds and van der Waals forces, with a less dramatic effect on water activity. Therefore, at a given solute weight fraction, inorganic solutions typically exhibit a lower water activity than organic solutions. Applying the examples shown in Fig. 4 to the atmospheric situation we find that at high and intermediate relative humidities $T_{\mathrm{g}}$ of $\mathrm{H}_{2} \mathrm{SO}_{4}$ is too low to be of atmospheric relevance. Similar conclusions result from an analysis of $\mathrm{HNO}_{3}$ and $\mathrm{NH}_{4} \mathrm{HSO}_{4}$ solutions (not shown). Moreover, at low relative humidities inorganic substances present in the atmosphere tend to crystallize instead of forming glasses: for example, we did not observe glass formation in ammonium sulfate solutions due to the crystallization of $\left(\mathrm{NH}_{4}\right)_{2} \mathrm{SO}_{4}$. In contrast, organic solutes with properties similar to glucose may readily form glasses under atmospheric conditions. Therefore, we have investigated $T_{\mathrm{g}}$ of aqueous solutions of a large variety of organic substances. As discussed above, the glass transition temperatures are required as a function of water activity for atmospheric applications. The AIM-model by Clegg et al. (1998) allows the calculation of the water activity in inorganic ionic solutions typically found in the atmosphere over a wide temperature and con- centration range. For most organic substances of interest no such parameterizations are available, since most of the existing $a_{\mathrm{w}}$ data were measured at ambient temperatures or above. Group contribution methods such as UNIFAC (Fredenslund et al., 1975) are often inaccurate for the prediction of activity coefficients of multi-functional organics and usually they are not parameterized for use at low temperatures. Therefore, we have measured not only $T_{\mathrm{g}}$ but also $a_{\mathrm{w}}$ of the investigated solutions of organics with a commercial dew point water activity meter, see Appendix A4 for details, in the temperature range between $289 \mathrm{~K}$ and $313 \mathrm{~K}$. This data together with $a_{\mathrm{w}}$ values derived from the melting point depression temperatures below $273 \mathrm{~K}$ were used to extrapolate water activities to low temperatures and, thus, allow an estimate of $a_{\mathrm{w}}$ at the measured $T_{\text {hom }}$ and $T_{\mathrm{g}}$ values (see Appendix A4).

\section{$6 T_{g}$ in binary aqueous organic solutions}

In the previous section we have seen that organic aerosol constituents seem to have a tendency to form glasses at atmospherically relevant conditions (i.e. temperatures, compositions and relative humidities). Hence, we focus the subsequent discussion on glass transitions of pure organic or organic-rich aqueous solutions. Figure 5 shows the glass transition temperatures together with homogeneous ice nucleation and ice melting temperatures for various aqueous organic solutions as a function of the solution water activity. The raw data as a function of the solute weight fraction are listed in Table A1 and the conversion to the water activity scale has been performed as explained in the previous 
section and Appendix A4. The investigated substances have either been identified in atmospheric aerosols or represent substances that are atmospherically relevant in terms of functional groups and molar mass. Panel (a) depicts the experimental results for aqueous solutions of polyols with $4,6,8$ and 10 carbon atoms $(\mathrm{C} 4-\mathrm{C} 10)$ and a $\mathrm{C}: \mathrm{O}$ ratio of $2: 1$. The molar masses increase from $90.1 \mathrm{~g} \mathrm{~mol}^{-1}$ for the $\mathrm{C} 4$ polyol up to $220.3 \mathrm{~g} \mathrm{~mol}^{-1}$ for the $\mathrm{C} 10$ polyol. The $T_{\mathrm{g}}$ curves of the polyol solutions rise from $136 \mathrm{~K}$ at $a_{\mathrm{w}}=1$ to the glass temperatures of the pure polyols $\left(T_{\mathrm{g} 2}\right)$ at $a_{\mathrm{w}}=0$ (Note that only a limited range is shown in the figure). In general, the measured data points are well reproduced by the Gordon-Taylor equation shown as the colored curves in the figure. For a given $a_{\mathrm{w}}$, the glass transition temperature of a polyol solution is higher for higher molar mass of the polyol and this trend becomes more pronounced at lower water activities. The $T_{\mathrm{g}}$ curve for the $\mathrm{C} 4$ aqueous solutions is almost horizontal, since $T_{\mathrm{g} 2}$ of pure $\mathrm{C} 4$ is only about $20 \mathrm{~K}$ higher than that of pure water. The $T_{\mathrm{g}}$ curve for $\mathrm{C} 10$ aqueous solutions on the other hand strongly increases to the $T_{\mathrm{g}}$ value of pure $\mathrm{C} 10$. The $\mathrm{C} 6$ and $\mathrm{C} 8$ curves lie in between the $\mathrm{C} 4$ and the $\mathrm{C} 10$ curves corroborating a clear trend to higher $T_{\mathrm{g}}$ values with increasing molar mass for this series of polyols. The experimentally determined $T_{\mathrm{g}}^{\prime}$ values (open triangles) usually agree well with the $T_{\mathrm{g}}^{\prime}$ value derived from the intersections between the $T_{\mathrm{m}}$ curve and the $T_{\mathrm{g}}$ curves. The lowest measured $T_{\mathrm{g}}$ for the C6 solutions (green triangle at $T \approx 165 \mathrm{~K}$ and $a_{\mathrm{w}} \approx 0.8$ ) falls clearly below the homogeneous ice nucleation curve (solid black line). According to Koop et al. (2000), such a solution should freeze at a temperature of about $187 \mathrm{~K}$. However, neither an emulsion nor a bulk sample froze during the cooling cycle, but ice crystallization was observed upon warming to $\sim 10 \mathrm{~K}$ above $T_{\mathrm{g}}$ representing the case shown in Fig. 2c. The experimental $T_{\mathrm{m}}$ data fall almost perfectly onto the ice melting curve, indicating that the $a_{\mathrm{w}}$ parameterization for the polyols are accurate at these temperatures. The experimental $T_{\text {hom }}$ data of the polyol solutions show a small but systematic deviation from the homogenous ice nucleation curve that increases at lower water activities. It is not clear whether this deviation is due to uncertainties in the extrapolation of $a_{\mathrm{w}}$ to low temperatures or, alternatively, due to hindered ice formation as a consequence of the high viscosity of the C6, C8 and C10 solutions. Panel (b) compares data of aqueous solutions of a mono- (glucose), di- (sucrose) and trisaccharide (raffinose). The C:O ratio increases slightly from 6:6 for glucose, over 12:11 for sucrose up to 18:16 for raffinose. A similar trend as in panel (a) is observed: A larger molar mass of the organic solute leads to a higher $T_{\mathrm{g}}$ temperature at a given water activity. The $T_{\mathrm{g} 2}$ values of the anhydrous sugars were estimated based on the Gordon-Taylor equation as $296.1 \mathrm{~K}$, $335.7 \mathrm{~K}$ and $395.7 \mathrm{~K}$ for glucose, sucrose and raffinose, respectively. The data are in very good agreement with direct $T_{\mathrm{g}}$ measurements on the pure melt investigated in this study and by Roos (1993), with values of $296.1 \mathrm{~K}$ for glucose and
$333 \mathrm{~K}$ for sucrose. Note that for similar molar masses the $T_{\mathrm{g}}$ values of the pure sugars are higher than those of the pure polyols: The glass transition of pure glucose is about $70 \mathrm{~K}$ higher than that of the pure $\mathrm{C} 8$, although their molar masses differ by less than $2 \mathrm{~g} \mathrm{~mol}^{-1}$. This indicates that, in addition to molar mass, the molecular structure of the organic molecules significantly affects their glass temperature. The same trend holds also for the $T_{\mathrm{g}}^{\prime}$ values but it becomes weaker the higher the $a_{\mathrm{w}}$ values.

The experimentally determined $T_{\mathrm{g}}^{\prime}$ differ by about $5 \mathrm{~K}$ from those given by the intersection of the melting point and glass curves. This discrepancy may result from the experimental difficulty to determine $T_{\mathrm{g}}^{\prime}$ or from inaccuracies in the conversion from weight fraction to water activity. Several experimental $T_{\mathrm{g}}$ are clearly below the $T_{\mathrm{hom}}$ curve, e.g. for sucrose solutions with $w_{2}=0.5$ and 0.6 (see the green triangles at $a_{\mathrm{w}}$ values of 0.875 and 0.825 in Fig. $5 \mathrm{~b}$ ). In these experiments, the samples were hyperquenched at a very large cooling rate of $75 \mathrm{~K} \mathrm{~s}^{-1}$ (Luyet and Rasmussen, 1968). On the other hand, at moderate cooling rates of $10 \mathrm{~K} \mathrm{~min}^{-1}$ homogeneous ice nucleation was observed for sucrose solutions with $w_{2}=0.55$ (green square with a $T_{\text {hom }}$ of $\sim 210 \mathrm{~K}$, Miyata and Kanno, 2005). This comparison indicates that in the region close to the intersection of the $T_{\mathrm{hom}}$ and $T_{\mathrm{g}}$ curves also cooling rates are very important in determining whether glass formation or ice crystallization occur upon cooling. If a glass forms upon cooling in that area, then ice usually crystallizes upon warming (see discussion of Fig. 2). This was also observed for the two raffinose solutions with a $T_{\mathrm{g}}$ of $\sim 190 \mathrm{~K}$. The good agreement of the experimental $T_{\mathrm{m}}$ and $T_{\text {hom }}$ data with the predicted theoretical lines indicates again that the $a_{\mathrm{w}}$ parameterization for the sugar solutions are very accurate to low temperatures.

Panel (c) of Fig. 5 compares three polyols with almost the same $T_{\mathrm{g} 2}$ value, but with different $\mathrm{C}: \mathrm{O}$ ratios. At low water activities the $T_{\mathrm{g}}$ curve for glycerol $(\mathrm{C}: \mathrm{O}$ ratio of $1: 1)$ reveals the steepest slope followed by 1,2,6-hexanetriol (C:O ratio of 2:1) and 2,5-hexanediol (C:O ratio of 3:1) indicating that the glass transition of aqueous solutions depends also on the hydrophilicity of the substance. For the moderately hydrophobic 2,5-hexanediol the plasticizing effect of water is less effective than for the very hydrophilic glycerol. Thus the 2,5-hexanediol glass curve exhibits high values over a large water activity range and drops off rather steeply to the glass temperature of pure water only at high $a_{\mathrm{w}}$.

Finally, we show that glass formation is not restricted to organic molecules with hydroxy $(-\mathrm{OH})$ functionalities, but occurs also for other organic substances representing the water soluble organic compounds (WSOC) of atmospheric aerosols. Panel (d) depicts the $T_{\mathrm{g}}, T_{\mathrm{hom}}$ and $T_{\mathrm{m}}$ measurements for 4-hydroxy-3-methoxy mandelic acid, levoglucosan and an aqueous mixture of 5 different dicarboxylic acids (M5; consisting of malic acid, maleic acid, malonic acid, glutaric acid and methylsuccinic acid, see Appendix A1 for details). Levoglucosan is a biomass burning marker (e.g. Gra- 

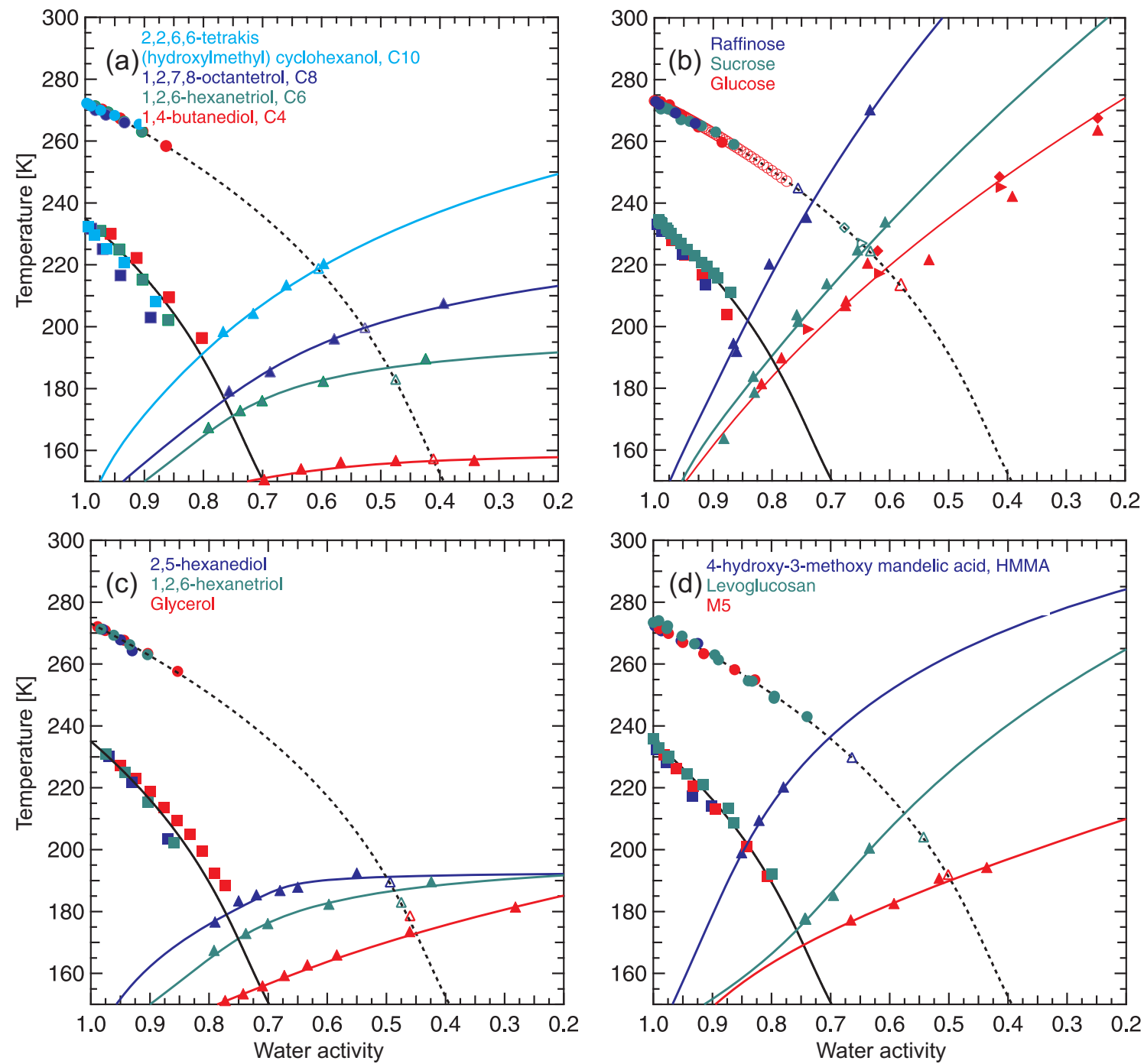

Fig. 5. State diagrams for several organic/water systems in the water activity scale. Circles: $T_{\mathrm{m}}$; squares: $T_{\mathrm{hom}}$; filled upward triangles and filled right pointed triangles: $T_{\mathrm{g}}$; open upward triangles filled diamonds, open diamonds and open right pointed triangles: $T_{\mathrm{g}}^{\prime}$. Colored lines: Glass transition curves calculated using Eqs. (1) and (A2) with the parameters given in Tables A3 and A4. Dashed and solid black lines: Ice melting and homogeneous ice freezing curves, respectively, according to Koop et al. (2000). (a) All data from this study; (b) Raffinose from this study; Sucrose: filled circles (Blond et al., 1997), filled squares (Miyata and Kanno, 2005), filled upward triangles (Luyet and Rasmussen, 1968), open upward triangle (Kilmartin et al., 2000), open diamond (Shalaev et al., 1996), open right pointed triangle (Roos, 1993) from literature; Glucose: Filled circles, filled squares, filled and open upward triangles all from this study, open circles (Young, 1957), filled diamonds (Seo et al., 2004) and filled right pointed triangle (Roos, 1993) from literature. (c) Hexanediol and Hexanetriol: all data from this study. Glycerol: Filled circles (Lerici et al., 1983), filled and open upward triangles (Luyet and Rasmussen, 1968) and filled squares (Miyata and Kanno, 2005) from literature. (d) All data from this study. M5 consists of malic acid, maleic acid, malonic acid, glutaric acid and methylsuccinic acid with mass ratios given in Appendix A1.

ham et al., 2002; Decesari et al., 2006), and 4-hydroxy-3methoxy mandelic acid (hereafter, HMMA) is an aromatic compound with a structure that is very similar to vanillic acid (4-hydroxy-3-methoxy benzoic acid), which has been proposed by Decesari et al. (2006) as a model substance of the WSOC in atmospheric aerosols. Furthermore, the M5 mixture was chosen because dicarboxylic acids are ubiquitous in the organic aerosol in remote and urban locations (e.g. Kawamura and Ikushima, 1993; Graham et al., 2002; Narukawa et al., 2003) and are thought to have primary (e.g. Kanakidou et al., 2005) and secondary sources (e.g. Ervens et al., 2004). 

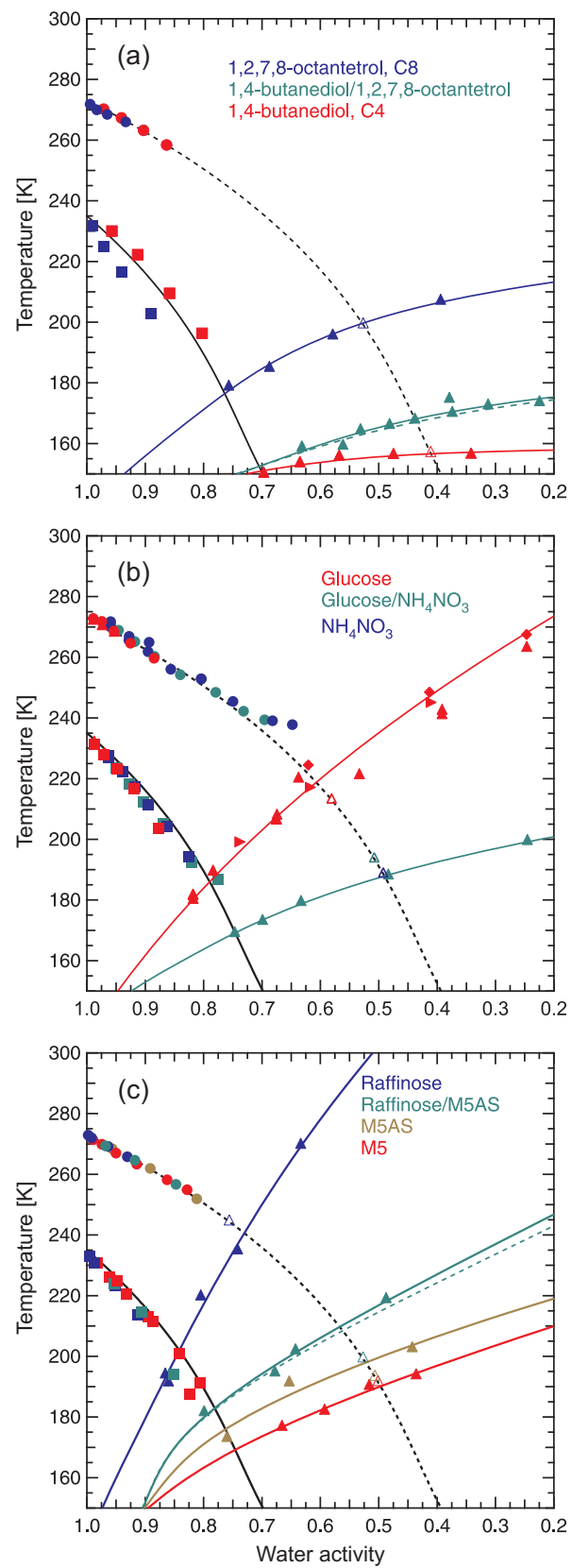

Fig. 6. State diagrams of multi-component solutions in the water activity scale. Circles: $T_{\mathrm{m}}$; squares: $T_{\text {hom }}$; filled triangles: $T_{\mathrm{g}}$; open triangles: $T_{\mathrm{g}}^{\prime}$. Solid colored curves: Glass curves calculated using Eqs. (1) and (A2) with the parameters given in Tables A3 and A4 except for the solid green curves in panel (a) and (b). There the $a_{\mathrm{W}}\left(w_{2}, T\right)$ is calculated using the ZdanovskiiStokes-Robinson (ZSR) mixing rule for ternary solutions (Stokes and Robinson, 1966). M5AS consists of $\left(\mathrm{NH}_{4}\right)_{2} \mathrm{SO}_{4}$ and the same dicarboxylic acids as in M5, but with slightly different mass ratios (see Appendix A1). For the ternary solutions (green symbols and lines) 1:1 mass ratios of the solutes were investigated. The green dashed lines were calculated according to Eq. 2.
The highest $T_{\mathrm{g}}$ curve is that of HMMA, which is in agreement with its large molar mass. Also $T_{\mathrm{g}}$ remains quite high even at large $a_{\mathrm{w}}$ values, because of its moderate hydrophobicity. The $T_{\mathrm{g}}-a_{\mathrm{w}}$ relationship of levoglucosan, a $\mathrm{C}_{6}-$ anhydrosugar, resembles that of the structurally similar $\mathrm{C}_{6^{-}}$ sugar glucose. The $T_{\mathrm{g}}$ curve of the aqueous M5 solutions is similar to that of glycerol solutions. This is due to the fact that the dicarboxylic acids exhibit a similar hydrophilicity as glycerol and $T_{\mathrm{g} 2}$ of the anhydrous M5 mixture is also quite low.

Two major points influencing the glass temperatures of organic substances can be summarized from Fig. 5: Firstly, the higher the molar mass of an organic solute the higher is $T_{\mathrm{g}}$ of its aqueous solution at a given water activity. Secondly, in aqueous solutions of more hydrophobic molecules, $T_{\mathrm{g}}$ remains at higher temperatures with increasing water content over a larger $a_{\mathrm{w}}$-range when compared to more hydrophilic molecules. Aerosol particles containing large and moderately hydrophobic water soluble organic molecules are most likely to form glasses at intermediate to high relative humidities in the upper troposphere (UT). However, the organic aerosol in the UT is typically an internal mixture of various organic molecules and inorganic salts and acids. Therefore, we also investigated $T_{\mathrm{g}}$ of selected multi-component solutions.

\section{$7 \quad T_{\mathrm{g}}$ of aqueous multi-component solutions}

Figure 6 shows $T_{\mathrm{g}}, T_{\mathrm{m}}$ and $T_{\text {hom }}$ for different multicomponent solutions. The organic mixture in panel (a) consists of a 1:1 mixture (by mass) of the polyols C4 and C8 with varying amounts of water. The Gordon-Taylor equation was used to determine $k$ and $T_{\mathrm{g} 2}$ of this mixture and the Zdanovskii-Stokes-Robinson (ZSR) mixing rule (Stokes and Robinson, 1966) was employed to predict the water activities of the ternary system from $a_{\mathrm{w}}$ data of the binary systems. The resulting ternary $T_{\mathrm{g}}$ curve (green solid line) is closer to that of $\mathrm{C} 4$ (solid red line), i.e. closer to the binary system with the lower glass transition temperatures. The dashed green line is not a fit to the data, but a $T_{\mathrm{g}}$ curve, that was predicted from the two binary $T_{\mathrm{g}}$ curves using a mixing rule that depends on the molar masses and weight fractions of the individual polyols:

$T_{\mathrm{g}}^{\mathrm{t}}\left(w_{\text {tot }}\right)=\frac{\frac{w_{2}(A)}{M_{\mathrm{w}}(A)} T_{\mathrm{g}}^{\mathrm{b}(\mathrm{A})}\left(w_{\text {tot }}\right)+\frac{w_{2}(B)}{M_{\mathrm{w}}(B)} T_{\mathrm{g}}^{\mathrm{b}(\mathrm{B})}\left(w_{\text {tot }}\right)}{\frac{w_{2}(A)}{M_{\mathrm{w}}(A)}+\frac{w_{2}(B)}{M_{\mathrm{w}}(B)}}$,

where $T_{\mathrm{g}}^{\mathrm{t}}$ is the glass transition temperature of the ternary solution containing both solutes $A$ and $B$, and $T_{\mathrm{g}}^{\mathrm{b}(\mathrm{A})}$ and $T_{\mathrm{g}}^{\mathrm{b}(\mathrm{B})}$ are the glass transition temperatures of binary solutions of either solute $A$ or $B$, respectively. $w_{\text {tot }}=w_{2}(A)+w_{2}(B)$ is the total solute weight fraction in the ternary solution and $w_{2}(A)$ and $w_{2}(B)$ are the individual weight fractions of the two solutes $A$ and $B$ in the ternary solution, respectively. $M_{\mathrm{w}}(A)$ 
and $M_{\mathrm{w}}(B)$ are the molar masses of the two solutes. The curve for the ternary system according to Eq. (2) (dashed green line) is in excellent agreement with the experimental data shown in Fig. 6, suggesting that $T_{\mathrm{g}}$ of ternary solutions consisting of two organics from the same chemical compound class can be predicted from the properties of the individual binary systems.

Panel (b) shows the $T_{\mathrm{g}}$ curve of a 1:1 mixture (by mass) of a non-dissociating organic compound (glucose) with a salt $\left(\mathrm{NH}_{4} \mathrm{NO}_{3}\right)$. The water activities of the ternary solutions were again calculated using the ZSR mixing rule. Unfortunately, the $T_{\mathrm{g}}$ values of binary $\mathrm{NH}_{4} \mathrm{NO}_{3}$ solutions could not be determined experimentally, because $\mathrm{NH}_{4} \mathrm{NO}_{3}$ always crystallized upon cooling before forming a glass. Only in dilute $\mathrm{NH}_{4} \mathrm{NO}_{3}$ solutions it was possible to determine $T_{\mathrm{g}}^{\prime}$ after homogeneous ice nucleation in the emulsion droplets (blue open triangle). The ternary glucose $/ \mathrm{NH}_{4} \mathrm{NO}_{3}$ glass curve is far below that of binary glucose solutions. Assuming a behavior similar to that of the mixture in panel (a) we expect the $T_{\mathrm{g}}$ curve for binary $\mathrm{NH}_{4} \mathrm{NO}_{3}$ solutions to be not far below the ternary curve, in agreement with the comparison of the $T_{\mathrm{g}}^{\prime}$ values determined for these systems.

Figure $6 \mathrm{c}$ shows $T_{\mathrm{g}}$ for solutions containing a eutonic mixture of $\left(\mathrm{NH}_{4}\right)_{2} \mathrm{SO}_{4}$ with the dicarboxylic acids of the M5 mixture (M5AS; the exact mixing ratios are given in Appendix A1 and differ slightly from those of the M5 mixture). M5AS was then mixed 1:1 (by mass) with raffinose and varying amounts of water and the corresponding $T_{\mathrm{g}}$ curve is shown as the green line. (Note that the $T_{\mathrm{g}}$ values of binary $\left(\mathrm{NH}_{4}\right)_{2} \mathrm{SO}_{4}$ solutions could not be determined experimentally, because crystallization of either $\left(\mathrm{NH}_{4}\right)_{2} \mathrm{SO}_{4}$ or ice was always observed). The water activities for the raffinose/M5AS and the M5AS systems were determined from experiments similar to those for the binary aqueous systems described in Sect. 5. The absolute $T_{\mathrm{g}}$ values as well as the shape of the $T_{\mathrm{g}}$ curve for the raffinose/M5AS solutions are much closer to the $T_{\mathrm{g}}$ curve of the M5AS system.

The dashed green line shows the $T_{\mathrm{g}}$ curve that was predicted from the two "binary" $T_{\mathrm{g}}$ curves (M5AS and raffinose) employing the mixing rule of Eq. (2) and using the molar masses of the undissociated compounds. Both green curves (predicted and fitted to the actual data) are consistent with the data and, thus, support the conclusion, that $T_{\mathrm{g}}$ in multicomponent aqueous solutions dominated by organic solutes can be estimated reasonably well from the $T_{\mathrm{g}}$ values of the binary solutions.

Because of the complex nature of the glass transition process and its intricate dependence on the characteristics of the different solutes, it is too early to generalize the results presented in this section. Nevertheless, based on the few multicomponent aqueous solutions investigated here, we suggest that $T_{\mathrm{g}}$ curves of aqueous multi-component solutions fall between those of the binary systems. Also, the location and shape of the ternary curve is typically more similar to that of the binary system with the lower $T_{\mathrm{g}}$ values. This behav- ior was observed for aqueous mixtures of organics and for organic/inorganic aqueous mixtures, that are dominated by organic solutes.

\section{$8 \mathbf{T}_{\mathrm{g}}^{\prime}$ and $\mathbf{T}_{\mathrm{g}}^{*}$ of organic solutes and of multi-component solutions}

As discussed above, $T_{\mathrm{g}}^{\prime}$ is an important indicator for the temperature and concentration range in which ice crystallization is inhibited (even if critical ice germs nucleated) at the cost of glass formation in an aqueous system. Also, we have shown that both $T_{\mathrm{g}}$ and $T_{\mathrm{g}}^{\prime}$ are dependent on the molar mass of an organic solute. Next, we will try to better constrain this dependence.

Based on experimental data of 55 commercial starch hydrolysis products, Levine and Slade (1986) found a linear relationship between $T_{\mathrm{g}}^{\prime}$ and the inverse molar mass of these compounds for a range of molar masses from $180 \mathrm{~g} \mathrm{~mol}^{-1}$ up to $39000 \mathrm{~g} \mathrm{~mol}^{-1}$. These results indicate that a larger molar mass of the organic molecules leads to a higher $T_{\mathrm{g}}^{\prime}$ value due to the increase in viscosity of the aqueous solutions with increasing molecular size of the solute. Figure 7a shows $T_{\mathrm{g}}^{\prime}$ of various organic solutes (filled symbols) as well as for multi-component solutions (open symbols) from this study, complemented with literature data of solutes with the same functional groups. The $T_{\mathrm{g}}^{\prime}$ values for all solutions increase with decreasing inverse molar mass (or increasing molar mass), from $156.8 \mathrm{~K}$ for the $\mathrm{C} 4$ polyol up to $244.4 \mathrm{~K}$ for raffinose. A linear trend, indicated by the solid black line represents well the data in a molar mass range from $90 \mathrm{~g} \mathrm{~mol}^{-1}$ to $\sim 500 \mathrm{~g} \mathrm{~mol}^{-1}$ and can be approximated as:

$T_{\mathrm{g}}^{\prime}=-7813.5 \cdot M_{\mathrm{w}}^{-1}+253.3$,

where $T_{\mathrm{g}}^{\prime}$ is given in $\mathrm{K}$ and $M_{\mathrm{w}}$ is the molar mass of the substance in $\mathrm{g} \mathrm{mol}^{-1}$. The dashed black lines in Fig. 7a depict the confidence bands for the linear fit on the level of one standard deviation. There is a maximum difference between the $T_{\mathrm{g}}^{\prime}$ values of organic solutions of roughly $25 \mathrm{~K}$ at a similar molar mass, which most likely is the result of the different chemical structures and hydrophilicities of the molecules, as discussed above. The C8 polyol and glucose have similar molar masses (blue and red circles at an inverse molar mass of $\sim 0.0055$ ), but their $T_{\mathrm{g}}^{\prime}$ differ by about $15 \mathrm{~K}$. $T_{\mathrm{g}}^{\prime}$ of the aromatic compound HMMA at $\sim 230 \mathrm{~K}$ is even higher than that of sucrose despite having only a molar mass that is $\sim 60 \%$ of that of sucrose. For the data shown in Fig. 7a, the molecules containing a ring structure seem to exhibit a higher $T_{\mathrm{g}}^{\prime}$ than open chain molecules.

Also included in Fig. 7a are $T_{\mathrm{g}}^{\prime}$ values of multi-component solutions (open symbols). The average molar masses of the multi-component solutions were calculated by averaging the masses of the compounds according to their molar ratios (all compounds were treated as undissociated). The $T_{\mathrm{g}}^{\prime}$ values 
of the multi-component solutions scatter slightly more than those of binary solutions, however, based on the present data it appears to be appropriate to conclude that $T_{\mathrm{g}}^{\prime}$ of both binary organic aqueous solutions and multi-component solutions that are dominated by organic solutes depend primarily on the molar mass of the solutes.

Besides $T_{\mathrm{g}}^{\prime}$, each $T_{\mathrm{g}}$ curve has another very important characteristic point in the state diagram: the intersection between the homogeneous ice freezing curve $T_{\text {hom }}$ and the glass transition curve $T_{\mathrm{g}}$. We define this point as $T_{\mathrm{g}}^{*}$, which adopts a unique value for every solute. $T_{\mathrm{g}}^{*}$ designates the region of crossover between homogeneous ice nucleation and glass formation: At lower solute concentrations (or higher $a_{\mathrm{w}}$ ) aqueous solution droplets will homogenously nucleate ice, and at higher solute concentrations (or lower $a_{\mathrm{w}}$ ) glass formation is more likely. Since no experimental technique exists to measure $T_{\mathrm{g}}^{*}$ directly, we derive it from the intersection of the $T_{\text {hom }}$ curve with the experimentally determined $T_{\mathrm{g}}$ curves in the state diagrams shown in Figs. 5 and 6.

In Fig. $7 \mathrm{~b}$ we show $T_{\mathrm{g}}^{*}$ for the investigated organic and multi-component solutions, again as a function of the inverse molar mass of the solutes. The data can be well described by a linear fit given by:

$T_{\mathrm{g}}^{*}=-5145.1 \cdot M_{\mathrm{w}}^{-1}+211.6$.

Here, $T_{\mathrm{g}}^{*}$ is given in $\mathrm{K}$ and $M_{\mathrm{w}}$ is the molar mass of the solute in $\mathrm{g} \mathrm{mol}^{-1}$. In general, the same trend as for $T_{\mathrm{g}}^{\prime}$ is observed: $T_{\mathrm{g}}^{*}$ increases with decreasing inverse molar mass (increasing molar mass). For a given molar mass, the substance with the lowest hydrophilicity shows the highest $T_{\mathrm{g}}^{*}$ values. For example, the aromatic compound HMMA exhibits the largest $T_{\mathrm{g}}^{*}$ although its molar mass is more than a factor of 2.5 smaller than that of raffinose. In addition, the $T_{\mathrm{g}}^{*}$ data of the multi-component solutions agree well with the data of the binary organic solutions. For a given substance, the difference between $T_{\mathrm{g}}^{\prime}$ and $T_{\mathrm{g}}^{*}$ is smaller when the $T_{\mathrm{g}}$ curve increases strongly at high water activities and becomes more flat at lower water activities as is typical for more hydrophobic solutes, such as the aromatic compound HMMA or 2,5hexanediol.

Both $T_{\mathrm{g}}^{\prime}$ and $T_{\mathrm{g}}^{*}$ have important implications for the atmospheric situation because they can be used as indicators of whether atmospheric aerosols are more likely to form ice particles or glasses at a given temperature and relative humidity. This will be explored in more detail in the following section.

\section{Atmospheric implications}

Highly viscous or glassy aerosol particles may affect several physical and chemical processes in the atmosphere: Chemical reactions are impeded in viscous solutions (e.g. Zahardis and Petrucci, 2007), and presumably will be inhibited in glassy aerosol particles, thereby leading to an extended aerosol lifetime with respect to chemical decomposition. The slow molecular diffusion of water within glassy aerosol particles can drastically retard or even entirely prevent water uptake from the gas phase and inhibit ice nucleation and/or ice growth. Water uptake by an aerosol increases its scattering intensity and, therefore, affects climate forcing by the direct aerosol effect. Moreover, water uptake is an essential process that precedes and accompanies cloud formation and may therefore also influence cloud properties and/or occurrences.

Gas and liquid phase water diffusion is typically fast enough to justify the assumption that aerosols are in equilibrium with ambient relative humidity. However, if diffusion within aerosol particles is drastically diminished, this assumption may no longer hold. The molecular diffusion of water within aqueous solutions is expressed by the diffusion coefficient $D_{\mathrm{H}_{2} \mathrm{O}}$, a quantity that is not well known for aqueous organic/inorganic solutions at low temperatures. Rampp et al. (2000) measured the self-diffusion coefficient of water in several aqueous carbohydrate solutions in the temperature range from $273 \mathrm{~K}$ to $353 \mathrm{~K}$. Their results indicate a reduction of $D_{\mathrm{H}_{2} \mathrm{O}}$ with increasing concentration and decreasing temperature.

A recent model study by He et al. (2006) allows for the calculation of $D_{\mathrm{H}_{2} \mathrm{O}}$ in aqueous glycerol, fructose, sucrose and trehalose solutions over the entire concentration range down to upper tropospheric temperatures. $D_{\mathrm{H}_{2} \mathrm{O}}$ in all these solutions rarely exceeds a value of $10^{-20} \mathrm{~m}^{2} \mathrm{~s}^{-1}$ at $T_{\mathrm{g}}$ over the entire $a_{\mathrm{w}}$ range. This implies that a water molecule would need a time interval $\Delta t$ of about one day to diffuse into an aerosol particle with a size of $\Delta x=50 \mathrm{~nm}$ :

$\Delta t=\frac{(\Delta x)^{2}}{D_{\mathrm{H}_{2} \mathrm{O}}}=\frac{\left(50 \cdot 10^{-9} \mathrm{~m}\right)^{2}}{10^{-20} \mathrm{~m}^{2} \mathrm{~s}^{-1}}=2.5 \cdot 10^{5} \mathrm{~s} \geq 1$ day.

Furthermore, $D_{\mathrm{H}_{2} \mathrm{O}}$ increases only moderately with increasing temperature and still exhibits values of $\sim 10^{-15} \mathrm{~m}^{2} \mathrm{~s}^{-1}$ at about $20 \mathrm{~K}$ above $T_{\mathrm{g}}$. This suggests that water uptake is significantly delayed in the temperature range just above $T_{\mathrm{g}}$ and completely inhibited once a glass has formed in these solutions.

Because the glass transition temperature of solutions dominated by organics primarily depends on the average molar mass of the solutes (see Fig. 7), one needs to know the molar mass range of aerosol constituents to estimate their $T_{\mathrm{g}}$. The fraction of low molar mass organic compounds in aerosol particles depends on gas/particle partitioning. Acetic acid and glyoxal with molar masses of $\sim 60 \mathrm{~g} \mathrm{~mol}^{-1}$ belong to the smallest organic compounds that partition to a certain extent into the condensed aerosol phase (Kawamura et al., 1996a,b; Fisseha et al., 2006). This lower molar mass limit might also apply to the UT, if we assume that the shift to the condensed phase due to lower temperatures is balanced by the opposite shift due to their lower concentrations in the upper troposphere.

The aerosol components with the highest molar masses are HULIS (humic-like substances) with masses up to 

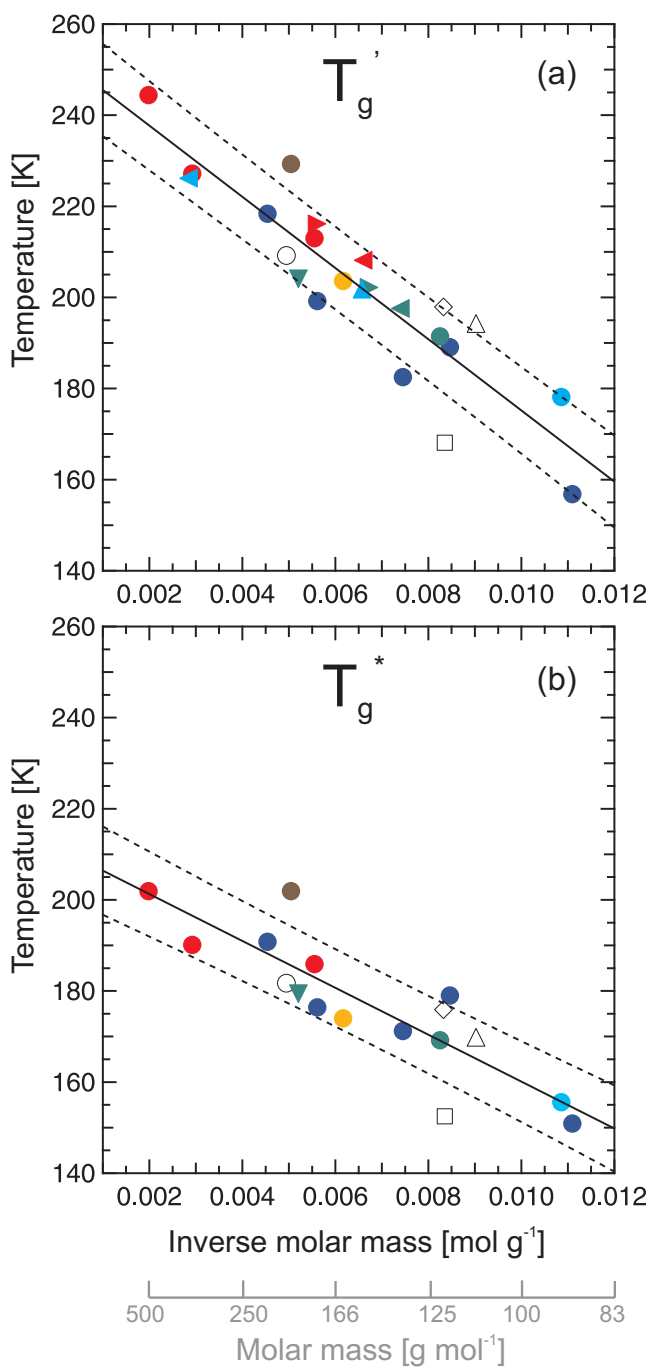

Fig. 7. $T_{\mathrm{g}}^{\prime}$, panel (a), and $T_{\mathrm{g}}^{*}$, panel (b), for aqueous solutions as a function of the inverse molar mass of the solute. Filled and open symbols stand for aqueous organic and multi-component solutions, respectively. The colors of the filled symbols denote the different substances or compound classes. Red: sugars; blue: polyols; light blue: sugar alcohols; green: dicarboxylic acids; brown: HMMA; orange: levoglucosan. Filled circles: data from this study except that of sucrose (red circle with a $T_{\mathrm{g}}^{\prime}$ of $227.2 \mathrm{~K}$, Roos, 1993) and glycerol (light blue circle with a $T_{\mathrm{g}}^{\prime}$ of $178.2 \mathrm{~K}$, Luyet and Rasmussen, 1968). Light blue left and upward pointed triangles: maltitol and xylitol (Roos, 1993); Green downward, left and right pointed triangles: citric, tartaric and malic acid, respectively (Maltini et al., 1997; Murray, 2008a); Red right and left pointed triangles: fructose and xylose (Roos, 1993); The open symbols are labeled as, circle: raffinose/M5AS, square: $\mathrm{C} 4 / \mathrm{C} 8$, triangle: glucose $/ \mathrm{NH}_{4} \mathrm{NO}_{3}$ and diamond: M5AS. Black solid lines: Linear fits according to Eqs. 3 and 4 for panels (a) and (b), respecitvely. The dashed black lines depict the confidence bands of the solid black lines on a one standard deviation level.

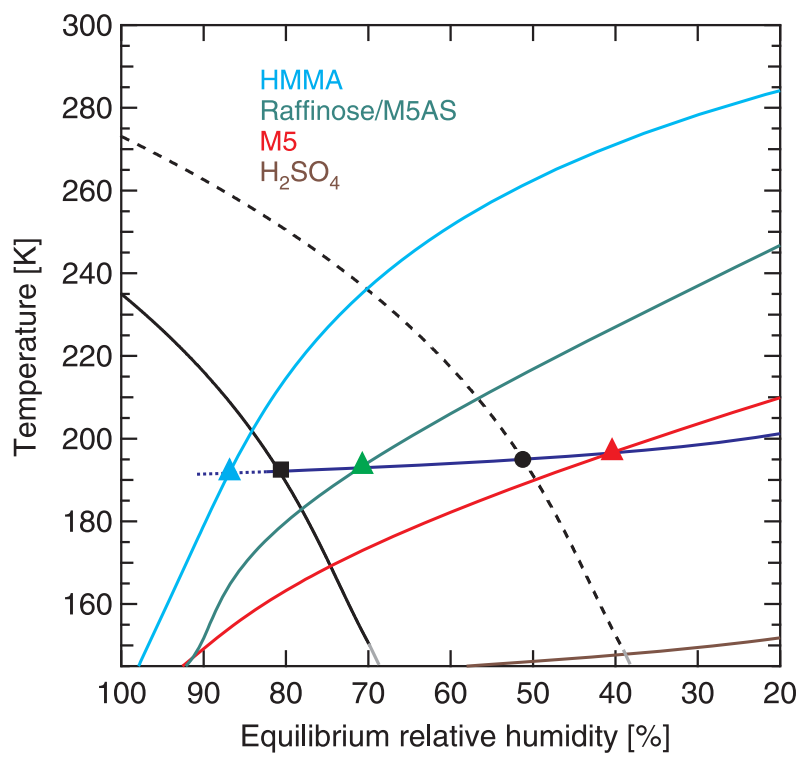

Fig. 8. Typical atmospheric trajectory (dark blue curve with symbols) as a function of the equilibrium relative humidity of the air. Solid black and dashed black lines: Homogeneous ice freezing and ice melting curve (the grey parts of each curve is an extrapolation from $150 \mathrm{~K}$ down to $145 \mathrm{~K}$ ). The cyan, green, red and brown curves depict the glass curves of HMMA, raffinose/M5AS, M5 and $\mathrm{H}_{2} \mathrm{SO}_{4}$, respectively. The black square and circle denote the relative humidities at the homogeneous ice freezing point, $\mathrm{RH}\left(T_{\text {hom }}\right)$ and at the frost point $\mathrm{RH}\left(T_{\text {frost }}\right)$ of the trajectory, respectively. The colored triangles are the intersections of the trajectory with the glass curves, which are labeled as $\mathrm{RH}\left(T_{\mathrm{g}}\right)$ in Fig. 9.

$500 \mathrm{~g} \mathrm{~mol}^{-1}$ and average molar masses in the range of 200$350 \mathrm{~g} \mathrm{~mol}^{-1}$ (Kiss et al., 2003). This substance class typically represents $20-50 \%$ of the total water soluble organic carbon (Krivácsy et al., 2008). A molar mass range from $60-500 \mathrm{~g} \mathrm{~mol}^{-1}$ is consistent with the results of Krivácsy et al. (2001), who measured aerosol molar mass at the high alpine station Jungfraujoch (Switzerland). Whether the average molar mass of an aerosol will be at the lower or higher end of this range depends strongly on the origin and history of air masses. Hence, for the following study of atmospheric scenarios, we define three different aerosol types: First, an aged highly hydrophilic aerosol containing predominantly low molar mass organics, such as the M5 mixture investigated above. Second, a biomass burning aerosol consisting of low to high molar mass organics and a minor fraction of inorganic molecules represented by the raffinose/M5AS mixture. Third, an aerosol dominated by organics with a larger fraction of high molar mass that is moderately hydrophilic such as HULIS, represented by HMMA. Finally, we use pure $\mathrm{H}_{2} \mathrm{SO}_{4}$ aerosols as an inorganic reference case. 


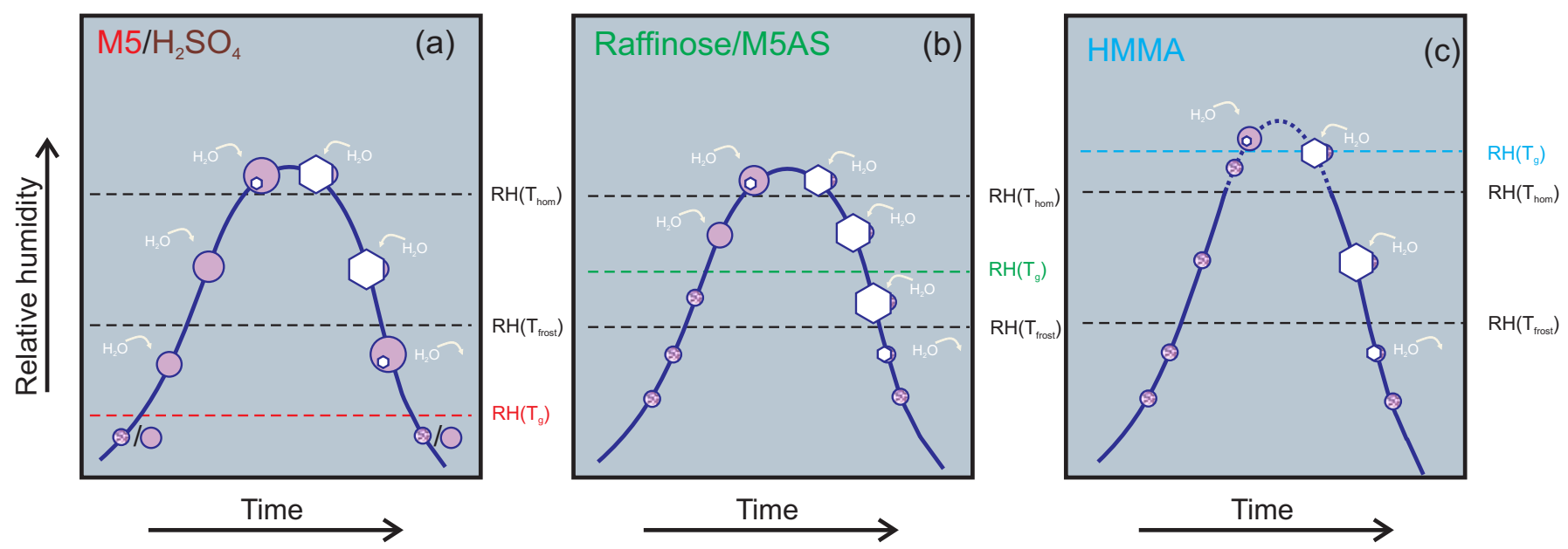

Fig. 9. Schemes for the physical states of model aerosols following the hypothetical trajectory shown in Fig. 8, starting from low to high RH and back to low RH. Panel (a): M5 and $\mathrm{H}_{2} \mathrm{SO}_{4}$; Panel (b): raffinose/M5AS; Panel (c): HMMA. The different symbols represent the different phases. Uniform-colored circles: liquid; Hexagon: ice; Spotted circles: glass. The white arrows denote the water exchange between the aerosol and the gas phase. $\mathrm{RH}\left(T_{\text {hom }}\right), \mathrm{RH}\left(T_{\text {frost }}\right)$ and $\mathrm{RH}\left(T_{\mathrm{g}}\right)$ are the relative humidities at the homogeneous ice freezing point, frost point and glass temperature of the trajectory and are linked to Fig. 8 with the black square, black bullet and the colored triangles, respectively.

Figure 8 depicts an upper tropospheric trajectory, that reaches the atmospheric frost point, i.e. ice saturation, at $\sim 195 \mathrm{~K}$ and for which homogeneous ice nucleation is expected to occur at $\sim 192 \mathrm{~K}$. Figure 9 shows schematically the physical states that the four model aerosol particles assume while following the trajectory shown in Fig. 8 from low to high relative humidities and back to low relative humidities.

Panel (a) of Fig. 9 shows the case of aerosols either consisting of an M5 mixture or of $\mathrm{H}_{2} \mathrm{SO}_{4}$. Both model aerosol particles pass through the same physical states along the trajectory except at low relative humidities when the $\mathrm{H}_{2} \mathrm{SO}_{4}$ particle is liquid and the M5 particle is a glass. $\left(\mathrm{A} \mathrm{H}_{2} \mathrm{SO}_{4}\right.$ aerosol particle would need temperatures below $160 \mathrm{~K}$ to turn into a glass for $\mathrm{RH}>20 \%$, see brown curve in Fig. 8). A glass-to-liquid transition of the M5 particle takes place at $\mathrm{RH} \approx 40 \%$ (red triangle in Fig. 8). The liquid M5 aerosol now starts to take up water and thus grows. ${ }^{1}$ Below the frost point, the air is supersaturated with respect to ice, but ice nucleation does not yet proceed unless heterogeneous ice nuclei are present. Once the trajectory has crossed the homogeneous ice freezing curve $(\mathrm{RH} \approx 81 \%$ equivalent to an ice saturation ratio $S_{\text {ice }}$ of $\sim 1.58$ at $\sim 192 \mathrm{~K}$ ) homogeneous ice nucleation occurs in the liquid aerosol and gas phase water will

\footnotetext{
${ }^{1}$ The glass-to-liquid transition upon increasing RH is most likely similar to a deliquescence process of a crystalline solid. The latter occurs as soon as the crystalline particle reaches its deliquescence relative humidity because water uptake starts from the surface of the particle leading to a liquid layer that propagates inward without the need for solid state diffusion. The same process is likely to be active in glassy particles when RH changes to a value above the glass transition curve.
}

be depleted due to the growth of ice. A freeze concentrated solution is rejected from the ice phase and may form an inclusion within the ice or a liquid layer or droplet attached to the ice surface as illustrated in Fig. 9a. The ice grows until the air is depleted to the frost point relative humidity. Upon decreasing $\mathrm{RH}$, when the trajectory has passed the frost point, $\mathrm{RH}\left(T_{\text {frost }}\right)$, the ice crystal shrinks due to evaporation. Below $\mathrm{RH} \approx 40 \%$, M5 turns into a glass, whereas $\mathrm{H}_{2} \mathrm{SO}_{4}$ remains liquid.

The aerosol in the second example, panel (b), consists of an inorganic/organic mixture representing a biomass burning aerosol. This aerosol particle is in a glassy state up to $\mathrm{RH} \sim 70 \%$. Due to negligible water diffusion within the glassy particle, the solute concentration remains at that lower relative humidity value where the glass was formed. Hence, the particles are not in equilibrium with the gas phase relative humidity and only begin to take up water after passing the glass-to-liquid transition (green line). If relative humidity increases at a low enough rate, the particle's $a_{\mathrm{w}}$ equilibrates with the gas phase $\mathrm{RH}$ and ice nucleates at $\mathrm{RH}\left(T_{\text {hom }}\right)$ as indicated in Fig. 9b. However, if the particle's $a_{\mathrm{w}}$ lags behind the gas phase RH in a large updraft, homogeneous ice nucleation might be retarded. When ice forms, the freeze concentrated solution vitrifies (indicated by the spotted sphere segment attached to the ice crystal), because $\mathrm{RH}\left(T_{\text {frost }}\right)<\mathrm{RH}\left(T_{\mathrm{g}}^{\prime}\right)$. Ice evaporation begins when the trajectory passes below the frost point RH leaving behind a glassy aerosol particle.

In the third example, the aerosol is represented by a rather hydrophobic and large molecule with a high $T_{\mathrm{g}}^{*}$. An HMMA aerosol is in a glassy state over a large RH range and, hence, does not take up water. Since the aerosol particle is still 
glassy at $T_{\text {hom }}$, ice nucleation is inhibited and, thus, $\mathrm{RH}$ rises significantly above the threshold for homogeneous ice nucleation $\mathrm{RH}\left(T_{\text {hom }}\right)$. At $\mathrm{RH} \approx 87 \%$ or $S_{\text {ice }} \approx 1.70$, the glass-toliquid transition takes place and the liquid HMMA aerosol particle may take up water vapor and nucleate ice. However, it is likely that ice nucleation and growth is still slow because of the reduced diffusion within the aerosol particle.

Two notes have to be added to the above discussion. For simplicity, we neglected the Kelvin effect, which starts to become important for particles with diameters smaller than $200 \mathrm{~nm}$. Since in the upper troposphere small particles with diameters of roughly $50 \mathrm{~nm}$ prevail (e.g. Jensen et al., 2005) the Kelvin effect shifts homogeneous ice nucleation to higher supersaturations in these regions (an increase in $S_{\text {ice }}$ of $\sim 0.1$ for $50 \mathrm{~nm}$ particles at $192 \mathrm{~K}$ ). An analogous increase applies to the glass-to-liquid transition and subsequent ice nucleation, potentially leading to $S_{\text {ice }}>1.8$ for $50 \mathrm{~nm}$ particles in panel (c) of Fig. 9. We also think that heterogeneous ice nucleation by a deposition mechanism on a glassy aerosol is unlikely since nanometer-sized glassy particles exhibit a smooth convex surface that is disordered on a molecular level - characteristics that are converse to those that are known to promote heterogeneous nucleation such as the presence of kinks and steps or a molecular match with the ice lattice.

The examples discussed above all assume a homogeneous, completely internally mixed aerosol. Single particle in-situ measurements show that a large fraction, but not the entire upper tropospheric aerosol is internally mixed (Murphy et al., 2006). If an air parcel contains a range of $\mathrm{H}_{2} \mathrm{SO}_{4}$-rich to organic-rich particles, homogeneous ice nucleation will occur first in the $\mathrm{H}_{2} \mathrm{SO}_{4}$-rich particles with the lowest viscosity that adapt fastest to the increasing relative humidity, similar to model calculations with reduced accommodation coefficients for organic aerosols (Kärcher and Koop, 2005). These newly formed ice crystals start to deplete the gas phase water to values below the threshold of $S_{\text {ice }}$ for homogeneous ice nucleation leaving the organic-rich aerosol particles unfrozen. Such a fractionation was indeed observed by DeMott et al. (2003) and Cziczo et al. (2004) who found that organicenriched aerosol particles were less abundant than sulfate aerosol particles in the residues of ice cloud particles, and that organic-enriched aerosol particles remained unfrozen to higher RH. The measurements by Cziczo et al. (2004) have been performed in the temperature range between $196 \mathrm{~K}$ and $225 \mathrm{~K}$. At these temperatures organic-rich particles are likely to be present as glasses at low RH but turn into liquids before $\mathrm{RH}\left(T_{\text {hom }}\right)$ is reached. This corresponds to the scenario outlined in Fig. $9 \mathrm{~b}$ with a retarded water uptake starting only after the glass-to-liquid transition has occurred. Based on the data in Fig. 7 we consider it unlikely that atmospheric aerosol particles are in the glassy state when they reach the homogeneous ice nucleation threshold at temperatures above $\sim 202 \mathrm{~K}$, but below this temperature we expect a significant impact on ice nucleation depending on the average molar mass of the aerosol constituents.
If ice nucleation is retarded in aqueous organic aerosol particles in an externally mixed aerosol, then selective ice formation in inorganic particles may also influence the composition of the aged upper tropospheric aerosol because particles that have grown ice start to sediment and may not be available for further ice cloud cycles. Organic-rich, glassy aerosols may therefore become enriched in aged air masses, because they do not sediment and are also not prone to chemical decomposition. Such an aerosol would not form an ice cloud at the homogeneous ice nucleation threshold but only after the glass-to-liquid transition has occurred.

High $S_{\text {ice }}$ values up to 2.0 have indeed been observed in recent field campaigns (Jensen et al., 2005; Lawson et al., 2008) and experiments (Möhler et al., 2005), leading to a debate about the principle understanding of ice cloud formation (Peter et al., 2006) and water vapor measurements in the UT. We propose that the presence of organic glassy aerosol might be able to explain some of these observations. This hypothesis is indirectly supported by a recent field study by Denkenberger et al. (2007). In single-particle measurements they observed that the highest degree of oligomerization was observed when the aerosol was photochemically aged and acidic. Therefore, the aged aerosol in the upper troposphere might indeed contain a high fraction of HULIS and, therefore, might be present as glasses up to high relative humidities, with implications as discussed above.

\section{Conclusions}

To answer the title question of this study, "Do atmospheric aerosols form glasses?", we investigated the glass transition temperatures $T_{\mathrm{g}}$ of a series of aqueous inorganic, organic and multi-component solutions as a function of the solute concentration using a differential scanning calorimeter. The measured $T_{\mathrm{g}}$ values were transformed from the concentration to the water activity (= relative humidity) scale, which is more appropriate for atmospheric applications. The state diagrams determined in this way and the atmospheric scenarios discussed above lead us to suggest that organic-rich aerosols might indeed be present in a glassy state in the atmosphere. In addition, the data shown above support a number of additional conclusions:

1. Glass formation was observed in most of the investigated aqueous solutions. At smaller concentrations homogeneous ice nucleation occurred in all solutions. At larger concentrations, typically at solute weight fractions above $0.3-0.6$, depending on the type of solute, glass formation occurred. Increasing solute concentrations lead to a higher $T_{\mathrm{g}}$ which can be described by the Gordon-Taylor equation over the entire concentration range.

2. Aqueous inorganic solutions containing sulfuric acid, ammonium bisulfate or nitric acid form glasses at high 
solute concentrations, but $T_{\mathrm{g}}$ rarely exceed $180 \mathrm{~K}$. Ammonium sulfate and ammonium nitrate solutions did not form glasses when using moderate cooling rates, because either ice or the solute precipitated beforehand. Therefore, we consider it unlikely that such inorganic solutions form glasses under atmospheric conditions, although we note that other inorganic solutes exist, such as $\mathrm{Ca}\left(\mathrm{NO}_{3}\right)_{2}$, that are known to be potent glass formers (Angell et al., 1981).

3. Aqueous organic and multi-component solutions (dominated by organic solutes) undergo glass transitions typically at higher temperatures than inorganic solutions at similar concentrations. $T_{\mathrm{g}}$ of such solutions depend predominantly on the molar mass of the organic solute with a larger molar mass leading to a higher $T_{\mathrm{g}}$. To a lesser extent $T_{\mathrm{g}}$ also depends on the hydrophilicity of the molecules, with more hydrophobic molecules showing higher $T_{\mathrm{g}}$ values at similar concentrations.

4. The $T_{\mathrm{g}}$ curves of the multi-component solutions are located between the $T_{\mathrm{g}}$ curves of the binary solutions closer to that binary system with the lower $T_{\mathrm{g}}$. We have presented a preliminary mixing rule to predict $T_{\mathrm{g}}$ in multi-component solutions, however, the complexity of the glass transition process requires further studies to confirm its general applicability.

5. Chemical reactions are impeded in viscous aerosol particles (Zahardis and Petrucci, 2007) and might be even inhibited completely in glassy aerosol particles. This may increase the lifetime of the aerosol with respect to chemical decomposition.

6. We suggest that water uptake is diminished or even fully inhibited for highly viscous or glassy aerosols, respectively. Water uptake in an aerosol particle can be altered at least up to $235 \mathrm{~K},\left(T_{\mathrm{g}}^{\prime}\left(500 \mathrm{~g} \mathrm{~mol}^{-1}\right) \approx 235 \mathrm{~K}\right.$, see Eq. 3), since this process can also be hindered above the frost point. It should be noted, that $T_{\mathrm{g}}^{\prime}$ of a molar mass of $150 \mathrm{~g} \mathrm{~mol}^{-1}$ still exhibits a value of roughly $200 \mathrm{~K}$, indicating that also smaller organic molecules might slow the water uptake of aerosol particles significantly. It is therefore likely that organic-enriched aerosol particles are not in equilibrium with the gas phase when exposed to larger updrafts impeding the freezing of such aerosols, which is supported by recent field studies (DeMott et al., 2003; Cziczo et al., 2004). This might lead to an extended lifetime and enrichment of such aerosols in the upper troposphere, because of a reduced removal via sedimentation processes.

7. Ice nucleation is inhibited at the homogeneous ice nucleation threshold when the aerosol is in a glassy state which leads to higher ice supersaturations than expected for liquid aerosols. Such supersaturations are indeed observed at low temperatures in recent field studies (Jensen et al., 2005; Peter et al., 2006; Lawson et al., 2008). Aerosol particles containing large and moderate hydrophobic organic molecules are most likely to form glasses at intermediate to high relative humidities in the atmosphere. Based on molecular mass distributions of the organics measured in tropospheric aerosols (e.g. Krivácsy et al., 2001), glassy aerosol particles become an important obstruction for ice nucleation below $\sim 202 \mathrm{~K},\left(T_{\mathrm{g}}^{*}\left(500 \mathrm{~g} \mathrm{~mol}^{-1}\right) \approx 202 \mathrm{~K}\right.$, see Eq. 4). Furthermore, because of vitrification organic-enriched aerosols might lead to cirrus clouds with smaller ice particle number densities when compared to inorganic aerosols, which will influence the radiative effect of cirrus.

In order to fully assess the influence of glassy aerosols on the direct and indirect aerosol effect on the local single cloud level as well as on the regional to global level, microphysical and/or large scale model studies are required to incorporate glass formation processes. Furthermore, our study shows that a better knowledge of the chemical composition of the upper tropospheric aerosol is required to improve understanding of ice cloud formation and upper tropospheric humidity.

\section{Appendix A}

\section{Experimental}

A1 Differential scanning calorimeter and sample preparation

Emulsified and bulk samples of aqueous organic, inorganic and multi-component solutions have been investigated with a differential scanning calorimeter (DSC, TA Instruments). The emulsions were prepared by two alternative methods: In one procedure, four parts of a $23 \mathrm{wt} \%$ lanolin/mineral oil solution (Fluka/Aldrich) was added to one part of the aqueous solution. This mixture was stirred with a rotor-stator homogenizer (Polytron PT 1300 D with a PT-DA 1307/2EC dispersing aggregate) for $40 \mathrm{~s}$ at $7000 \mathrm{rpm}$ leading to droplets with diameters in the range of $0.5 \mu \mathrm{m}$ to $5 \mu \mathrm{m}$. In the other procedure, one part of a $7 \mathrm{wt} \%$ solution of SPAN60 (Sigma) in a 1:1 mixture of methylcyclopentane/methylcyclohexane (Merck) was added to one part of the aqueous solution. This mixture was stirred with a homogenizer (IKA Ultra-Turrax $\mathrm{T} 25$ basic) for $10 \mathrm{~min}$ at $22000 \mathrm{rpm}$. The mass of the emulsified samples were typically between 8 and $30 \mathrm{mg}$. Bulk samples were directly pipetted into the DSC pan and their masses were in the range of 8 to $25 \mathrm{mg}$. The pans were immediately hermetically sealed to prevent any evaporation of the samples. The remaining gas volume in the pan is small compared to the volume of the sample and thus the sample concentration can be considered to remain constant. 
Table A1. Homogeneous ice freezing $T_{\text {hom }}$, ice melting $T_{\mathrm{m}}$ and glass temperatures $T_{\mathrm{g}}$ of various aqueous organic and inorganic solutions. All temperatures are given in Kelvin and $w_{2}$ denotes the concentration in solute weight fraction. $M_{\mathrm{W}}$ is the molar mass of the molecule. The mean molar mass, $\bar{M}_{\mathrm{W}}$, for the M5 mixture is calculated by weighting the weight fraction ratios of each compound with its molar mass, whereby all acids are treated as undissociated.

\begin{tabular}{|c|c|c|c|c|c|c|c|c|c|c|c|c|c|c|c|}
\hline \multicolumn{4}{|c|}{$\begin{array}{l}\text { 1,4-butanediol, } \mathrm{C} 4 \\
M_{\mathrm{W}}=90.1 \mathrm{~g} \mathrm{~mol}^{-1}\end{array}$} & \multicolumn{4}{|c|}{$\begin{array}{l}\text { 2,5-hexanediol } \\
M_{\mathrm{W}}=118.2 \mathrm{~g} \mathrm{~mol}^{-1}\end{array}$} & \multicolumn{4}{|c|}{$\begin{array}{l}\text { 1,2,6-hexanetriol, C6 } \\
M_{\mathrm{W}}=134.2 \mathrm{~g} \mathrm{~mol}^{-1}\end{array}$} & \multicolumn{4}{|c|}{$\begin{array}{l}\text { 1,2,7,8-octanetetrol, C8 } \\
M_{\mathrm{W}}=178.2 \mathrm{~g} \mathrm{~mol}^{-1}\end{array}$} \\
\hline$w_{2}$ & $T_{\text {hom }}$ & $T_{\mathrm{m}}$ & $T_{\mathrm{g}}$ & $w_{2}$ & $T_{\text {hom }}$ & $T_{\mathrm{m}}$ & $T_{\mathrm{g}}$ & $w_{2}$ & $T_{\text {hom }}$ & $T_{\mathrm{m}}$ & $T_{\mathrm{g}}$ & $w_{2}$ & $T_{\text {hom }}$ & $T_{\mathrm{m}}$ & $T_{\mathrm{g}}$ \\
\hline 0.101 & 230.0 & 270.2 & & 0.100 & 230.2 & 271.2 & & 0.096 & 231.0 & 271.3 & & 0.098 & 231.7 & 271.8 & \\
\hline 0.199 & 222.2 & 267.3 & & 0.199 & 221.8 & 267.8 & & 0.199 & 225.0 & 269.3 & & 0.198 & 225.1 & 270.0 & \\
\hline 0.304 & 209.5 & 263.2 & & 0.301 & 203.5 & 264.3 & & 0.302 & 215.2 & 266.3 & & 0.296 & 216.6 & 268.5 & \\
\hline 0.396 & 196.3 & 258.4 & & 0.403 & & & 176.0 & 0.394 & 202.1 & 263.0 & & 0.408 & 203.0 & 266.0 & \\
\hline 0.499 & & & 150.0 & 0.501 & & & 182.8 & 0.489 & & & 166.9 & 0.603 & & & 178.7 \\
\hline 0.604 & & & 153.4 & 0.589 & & & 184.8 & 0.606 & & & 172.3 & 0.698 & & & 184.9 \\
\hline 0.700 & & & 155.6 & 0.712 & & & 186.2 & 0.672 & & & 175.5 & 0.803 & & & 195.5 \\
\hline 0.799 & & & 156.2 & 0.787 & & & 187.3 & 0.794 & & & 181.8 & 0.902 & & & 207.0 \\
\hline 0.890 & & & 156.3 & 0.894 & & & 191.9 & 0.897 & & & 189.1 & & & & \\
\hline \multicolumn{4}{|c|}{$\begin{array}{l}\text { C10 polyol } \\
M_{\mathrm{W}}=220.3 \mathrm{~g} \mathrm{~mol}^{-1}\end{array}$} & \multicolumn{4}{|c|}{$\begin{array}{l}\text { HМMА } \\
M_{\mathrm{W}}=198.2 \mathrm{~g} \mathrm{~mol}^{-1}\end{array}$} & \multicolumn{4}{|c|}{$\begin{array}{l}\text { Levoglucosan } \\
M_{\mathrm{W}}=162.1 \mathrm{~g} \mathrm{~mol}^{-1}\end{array}$} & \multicolumn{4}{|c|}{$\begin{array}{l}\text { Glucose } \\
M_{\mathrm{W}}=180.2 \mathrm{~g} \mathrm{~mol}^{-1}\end{array}$} \\
\hline$w_{2}$ & $T_{\text {hom }}$ & $T_{\mathrm{m}}$ & $T_{\mathrm{g}}$ & $w_{2}$ & $T_{\text {hom }}$ & $T_{\mathrm{m}}$ & $T_{\mathrm{g}}$ & $w_{2}$ & $T_{\text {hom }}$ & $T_{\mathrm{m}}$ & $T_{\mathrm{g}}$ & $w_{2}$ & $T_{\mathrm{hom}}$ & $T_{\mathrm{m}}$ & $T_{\mathrm{g}}$ \\
\hline 0.100 & 232.3 & 272.2 & & 0.102 & 232.5 & 272.4 & & 0.095 & 232.8 & 272.8 & & 0.100 & 231.2 & 272.8 & \\
\hline 0.194 & 229.6 & 271.4 & & 0.287 & 228.1 & 270.7 & & 0.193 & 229.7 & 271.5 & & 0.197 & 227.9 & 271.8 & \\
\hline 0.303 & 225.1 & 270.0 & & 0.503 & 217.2 & 267.6 & & 0.200 & 230.1 & 272.3 & & 0.297 & 223.2 & 268.6 & \\
\hline 0.396 & 220.7 & 268.3 & & 0.600 & 214.2 & 266.7 & & 0.318 & 224.5 & 269.1 & & 0.398 & 216.7 & 264.7 & \\
\hline 0.501 & 208.2 & 265.5 & & 0.695 & & & 198.4 & 0.395 & 221.0 & 266.5 & & 0.500 & 203.8 & 259.7 & \\
\hline 0.652 & & & 197.9 & 0.746 & & & 208.9 & 0.490 & 213.2 & 263.0 & & 0.599 & & & 180.9 \\
\hline 0.707 & & & 203.7 & 0.797 & & & 219.7 & 0.503 & 208.8 & 261.4 & & 0.649 & & & 189.3 \\
\hline 0.757 & & & 212.9 & & & & & 0.600 & 192.2 & 254.5 & & 0.760 & & & 206.2 \\
\hline \multirow[t]{6}{*}{0.802} & & & 219.8 & & & & & 0.663 & & & 177.3 & 0.761 & & & 207.7 \\
\hline & & & & & & & & 0.665 & & & 177.1 & 0.789 & & & 220.0 \\
\hline & & & & & & & & 0.728 & & & 184.6 & 0.849 & & & 221.1 \\
\hline & & & & & & & & 0.797 & & & 200.0 & 0.907 & & & 241.6 \\
\hline & & & & & & & & & & & & 0.950 & & & 263.1 \\
\hline & & & & & & & & & & & & 1.000 & & & 296.1 \\
\hline \multicolumn{4}{|c|}{$\begin{array}{l}\text { Raffinose } \\
M_{\mathrm{W}}=504.5 \mathrm{~g} \mathrm{~mol}^{-1}\end{array}$} & \multicolumn{4}{|c|}{$\begin{array}{l}\text { M5 } \\
\bar{M}_{\mathrm{W}}=121.2 \mathrm{~g} \mathrm{~mol}^{-1}\end{array}$} & \multicolumn{4}{|c|}{$\begin{array}{l}\mathrm{NH}_{4} \mathrm{HSO}_{4} \\
M_{\mathrm{W}}=115.1 \mathrm{~g} \mathrm{~mol}^{-1}\end{array}$} & \multicolumn{4}{|c|}{$\begin{array}{l}\mathrm{H}_{2} \mathrm{SO}_{4} \\
M_{\mathrm{W}}=98.1 \mathrm{~g} \mathrm{~mol}^{-1}\end{array}$} \\
\hline$w_{2}$ & $T_{\text {hom }}$ & $T_{\mathrm{m}}$ & $T_{\mathrm{g}}$ & $w_{2}$ & $T_{\text {hom }}$ & $T_{\mathrm{m}}$ & $T_{\mathrm{g}}$ & $w_{2}$ & \multicolumn{3}{|l|}{$T_{\mathrm{g}}$} & \multicolumn{3}{|c|}{$T_{\mathrm{g}}$} & \\
\hline 0.101 & 233.0 & 272.9 & & 0.100 & 230.7 & 271.4 & & 0.499 & 153.2 & & & 0.480 & 150.1 & & \\
\hline 0.201 & 230.7 & 272.0 & & 0.200 & 226.1 & 269.9 & & 0.597 & 156.9 & & & 0.575 & 156.4 & & \\
\hline 0.400 & 223.4 & 269.2 & & 0.300 & 220.6 & 267.0 & & 0.699 & 159.7 & & & 0.604 & 158.5 & & \\
\hline 0.514 & 213.5 & 265.8 & & 0.397 & 213.2 & 263.3 & & 0.748 & 162.6 & & & 0.651 & 161.2 & & \\
\hline 0.599 & & & 194.0 & 0.500 & 201.0 & 258.2 & & 0.795 & 167.5 & & & 0.724 & 168.3 & & \\
\hline 0.607 & & & 191.3 & 0.550 & 191.3 & 254.9 & & & & & & 0.794 & 175.4 & & \\
\hline 0.704 & & & 219.7 & 0.699 & & & 176.7 & & & & & 0.797 & 176.4 & & \\
\hline 0.772 & & & 234.8 & 0.755 & & & 182.0 & & & & & & & & \\
\hline \multirow[t]{2}{*}{0.849} & & & 269.6 & 0.803 & & & 190.2 & & & & & & & & \\
\hline & & & & 0.845 & & & 193.7 & & & & & & & & \\
\hline
\end{tabular}

All homogeneous ice freezing and ice melting temperatures were investigated in emulsions, whereas glass temperatures were determined in emulsified as well as in bulk samples. No significant difference in the glass temperatures of an emulsion versus a bulk sample was observed. $T_{\mathrm{g}}$ depends on the cooling rate of the experiment, with larger cooling rates leading to higher $T_{\mathrm{g}}$ (Debenedetti and Stillinger, 2001).
Ediger et al. (1996) state that changing the cooling rate by an order of magnitude may alter the glass temperature between 3 and $5 \mathrm{~K}$. Therefore, cooling and heating rates of $10 \mathrm{~K} \mathrm{~min}^{-1}$ are used for all glass experiments. Cooling rates of $10 \mathrm{~K} \mathrm{~min}^{-1}$ and heating rates of $1 \mathrm{~K} \mathrm{~min}^{-1}$ were used to observe homogeneous ice freezing and melting, respectively. The glass temperatures were determined as the onset 
Table A2. Homogeneous ice freezing $T_{\text {hom }}$, ice melting $T_{\mathrm{m}}$ and glass temperatures $T_{\mathrm{g}}$ of various aqueous multi-component solutions. All temperatures are given in Kelvin. $w_{2}$ denotes the total solute weight fraction of the 1:1 mixtures (mass ratio). The mean molar mass, $\bar{M}_{\mathrm{W}}$, for the multi-component solutions is calculated by weighting the weight fraction ratios of each compound with its molar mass, whereby all acids and salts are treated as undissociated.

\begin{tabular}{|c|c|c|c|c|c|c|c|c|c|c|c|c|c|}
\hline \multicolumn{2}{|c|}{$\begin{array}{l}\mathrm{C} 4 / \mathrm{C} 8 \\
\bar{M}_{\mathrm{W}}=119.7 \mathrm{~g} \mathrm{~mol}^{-1}\end{array}$} & \multicolumn{4}{|c|}{$\begin{array}{l}\text { Glucose } / \mathrm{NH}_{4} \mathrm{NO}_{3} \\
\bar{M}_{\mathrm{W}}=110.8 \mathrm{~g} \mathrm{~mol}^{-1}\end{array}$} & \multicolumn{4}{|c|}{$\begin{array}{l}\text { M5AS } \\
\bar{M}_{\mathrm{w}}=120.1 \mathrm{~g} \mathrm{~mol}^{-1}\end{array}$} & \multicolumn{4}{|c|}{$\begin{array}{l}\text { Raffinose/M5AS } \\
\bar{M}_{\mathrm{w}}=202.2 \mathrm{~g} \mathrm{~mol}^{-1}\end{array}$} \\
\hline$w_{2}$ & $T_{\mathrm{g}}$ & $w_{2}$ & $T_{\text {hom }}$ & $T_{\mathrm{m}}$ & $T_{\mathrm{g}}$ & $w_{2}$ & $T_{\mathrm{hom}}$ & $T_{\mathrm{m}}$ & $T_{\mathrm{g}}$ & $w_{2}$ & $T_{\mathrm{hom}}$ & $T_{\mathrm{m}}$ & $T_{\mathrm{g}}$ \\
\hline 0.503 & 158.7 & 0.200 & 223.56 & 268.9 & & 0.201 & 224.8 & 268.4 & & 0.194 & 224.1 & 269.4 & \\
\hline 0.600 & 159.2 & 0.300 & 218.22 & 265.2 & & 0.407 & 211.4 & 262.0 & & 0.393 & 214.7 & 264.6 & \\
\hline 0.644 & 164.3 & 0.400 & 212.39 & 260.3 & & 0.570 & 187.4 & 251.9 & & 0.556 & 194.0 & 256.7 & \\
\hline 0.702 & 166.0 & 0.500 & 205.13 & 254.2 & & 0.676 & & & 173.0 & 0.652 & & & 181.5 \\
\hline 0.746 & 167.8 & 0.600 & 192.29 & 248.4 & & 0.767 & & & 191.3 & 0.765 & & & 194.6 \\
\hline 0.800 & 174.7 & 0.661 & 186.89 & 242.2 & & 0.878 & & & 202.6 & 0.787 & & & 201.9 \\
\hline 0.802 & 170.0 & 0.700 & & 239.4 & 169.0 & & & & & 0.863 & & & 218.8 \\
\hline 0.847 & 172.5 & 0.740 & & & 173.1 & & & & & & & & \\
\hline \multirow[t]{3}{*}{0.902} & 173.6 & 0.781 & & & 179.3 & & & & & & & & \\
\hline & & 0.844 & & & 188.0 & & & & & & & & \\
\hline & & 0.900 & & & 199.4 & & & & & & & & \\
\hline
\end{tabular}

Table A3. $k$ and $T_{\mathrm{g} 2}$ values from the Gordon-Taylor equation, Eq. (1), for glass temperatures of various aqueous organic, inorganic and multi-component solutions. Also given are the uncertainties, $\sigma$, for both parameters on a one standard deviation level. All glass temperatures for the fit are from this study, except those of glycerol (Ablett et al., 1992), sucrose (Ablett et al., 1992; Roos, 1993) and $\mathrm{HNO}_{3}$ (Satoh and Kanno, 1982). In the case of glucose, also data of Roos (1993) and Seo et al. (2004) have been used for the fit.

\begin{tabular}{|c|c|c|c|c|}
\hline solute & $k$ & $\sigma_{k}$ & $T_{\mathrm{g} 2}$ & $\sigma_{T_{\mathrm{g} 2}}$ \\
\hline 1,4-butanediol, C4 & 0.49 & 0.13 & 158.4 & 1.1 \\
\hline 2,5-hexanediol & 0.25 & 0.04 & 192.4 & 1.3 \\
\hline 1,2,6-hexanetriol, C6 & 0.88 & 0.07 & 193.5 & 1.3 \\
\hline 1,2,7,8-octanetetrol, C8 & 1.47 & 0.13 & 217.8 & 2.1 \\
\hline C10 polyol & 1.88 & 0.20 & 258.6 & 5.2 \\
\hline HMMA & 3.45 & 0.27 & 293.6 & 6.6 \\
\hline Levoglucosan & 5.20 & 1.02 & 283.6 & 18.7 \\
\hline Glucose & 3.95 & 0.24 & 296.1 & 3.1 \\
\hline Sucrose & 4.86 & 0.20 & 335.7 & 3.6 \\
\hline Raffinose & 5.33 & 0.73 & 395.7 & 21.6 \\
\hline M5 & 2.59 & 0.46 & 222.2 & 6.3 \\
\hline Glycerol & 2.31 & 0.09 & 193.3 & 1.1 \\
\hline $\mathrm{H}_{2} \mathrm{SO}_{4}$ & 4.33 & 0.30 & 220.5 & 3.6 \\
\hline $\mathrm{NH}_{4} \mathrm{HSO}_{4}$ & 1.55 & 0.40 & 178.0 & 4.3 \\
\hline $\mathrm{HNO}_{3}$ & 2.44 & 0.16 & 194.4 & 2.6 \\
\hline $\mathrm{C} 4 / \mathrm{C} 8$ & 1.02 & 0.20 & 179.4 & 2.2 \\
\hline M5AS & 2.78 & 0.70 & 230.1 & 19.1 \\
\hline Raffinose/M5AS & 3.68 & 0.64 & 266.2 & 10.9 \\
\hline Glucose $/ \mathrm{NH}_{4} \mathrm{NO}_{3}$ & 4.23 & 0.16 & 229.2 & 1.7 \\
\hline
\end{tabular}

Atmos. Chem. Phys., 8, 5221-5244, 2008 point of the heat signal in the heating cycle, which represents a common evaluation procedure (e.g. Angell, 2002). The onset point of the glass signal was defined as the intersection of the tangent drawn at the point of greatest slope with the extrapolated baseline. The onset point is also used for the homogeneous ice freezing temperature evaluation, whereas the ice melting temperatures are determined at the maximum of the derivative of the heat flow signal of the ice melting peak. The glass transition of the freeze concentrated solution appears often just as a small signal and, thus, is sometimes hard to detect. Even more important, $T_{\mathrm{g}}^{\prime}$ depends significantly on the experimental procedure with deviations of $10 \mathrm{~K}$ in $T_{\mathrm{g}}^{\prime}$ for the same solute when different cooling/heating and/or annealing times are applied (This goes beyond the scope of this publication, but for further information see e.g. Roos, 1993). The temperature calibration of the DSC was performed with water, adamantane, cyclohexane, ammonium sulfate and indium, whereas a static as well as a cooling/heating rate dependent calibration has been performed. This leads to an uncertainty in absolute temperature of $\pm 0.6 \mathrm{~K}$ for the investigated cooling and heating rates. All aqueous solutions in this work were made with distilled and deionized water (Resistivity $\geq 18.2 \mathrm{M} \Omega \mathrm{cm}$ ). The following solutes were investigated: 1,4-butanediol (Riedel-de Haen, $>99 \%$ ), 2,5-hexanediol (Fluka, >97\%), 1,2,6-hexanetriol (Fluka, >95\%), 1,2,7,8-octanetetrol (Fluka, >97\%), 2,2,6,6Tetrakis(hydroxymethyl)cyclohexanol $\left(\mathrm{C}_{10} \mathrm{H}_{20} \mathrm{O}_{5}\right.$, Aldrich, $97 \%)$, DL-4-Hydroxy-3-methoxy mandelic acid $\left(\mathrm{C}_{9} \mathrm{H}_{10} \mathrm{O}_{5}\right.$, Sigma), levoglucosan (Fluka, >98\%), glucose (Sigma, $>99.5 \%$ ), raffinose (Sigma, >98\%), M5AS (a mixture of 30.7 wt $\%$ malonic acid (Fluka, >99\%), 14.7 wt $\%$ malic acid (Fluka, >99\%), $14.1 \mathrm{wt} \%$ maleic acid (Fluka, >99\%), 17.7 wt $\%$ glutaric acid (Fluka, >98\%), 7.4 wt\% methylsuccinic acid (Fluka, >97\%) and $15.4 \mathrm{wt} \%$ ammonium 
Table A4. Fit parameters $a$ to $g$ for the investigated aqueous solutions resulting from Eq. A2 for $a_{\mathrm{W}}\left(w_{2}, T\right)$.

\begin{tabular}{lllllccc}
\hline substance & $a$ & $b$ & $c$ & $d$ & $e$ & $f$ \\
\hline Glycerol & -1 & -0.8215 & 0.1033 & 0.001299 & 0.001864 & -0.006918 \\
1,4-butanediol, C4 & -1 & -0.8277 & -0.01681 & 0.004063 & -0.006156 & 0.007515 & -0.005343 \\
2,5-hexanediol & -1 & -0.8813 & -0.05436 & 0.002742 & 0.003809 & -0.00786 & 0.001295 \\
1,2,6-hexanetriol, C6 & -1 & -0.8983 & 0.0352 & 0.002273 & $1.775 \times 10^{-5}$ & -0.00294 & $6.518 \times 10^{-4}$ \\
1,2,7,8-octanetetrol, C8 & -1 & -0.9905 & 0.1408 & 0.0008393 & 0.003395 & -0.002149 & -0.00213 \\
C10 polyol & -1 & -1.0087 & 0.1794 & 0.0006095 & -0.0005971 & 0.005283 & -0.005327 \\
HMMA & -1 & -1.0023 & 0.07667 & 0.000737 & -0.0004777 & 0.002306 & -0.00256 \\
Levoglucosan & -0.99918 & -0.90978 & 0.021448 & -0.00045933 & 0.0035813 & 0.00026549 & -0.0033059 \\
Glucose & -1 & -0.91879 & 0.082547 & 0.00043113 & $-5.7258 \times 10^{-5}$ & -0.00037372 & 0.0 \\
Sucrose & -1 & -1.013 & 0.1704 & 0.001688 & -0.005151 & 0.009607 & -0.006142 \\
Raffinose & -1 & -1.0035 & 0.1206 & 0.0005149 & -0.000263 & 0.002451 & -0.002698 \\
M5 & -1 & -0.9802813 & 0.24119686 & 0.00235453 & -0.0043884 & 0.00248726 & -0.0004211 \\
M5AS & -1 & -0.86105 & 0.081162 & 0.0014332 & -0.0010453 & -0.0079497 & 0.006766 \\
\hline
\end{tabular}

sulfate (Sigma, 99.99+\%), Marcolli et al., 2004), M5 (a mixture of $28.5 \mathrm{wt} \%$ malonic acid, $16.7 \mathrm{wt} \%$ malic acid, $11.4 \mathrm{wt} \%$ maleic acid, $30.2 \mathrm{wt} \%$ glutaric acid and $13.3 \mathrm{wt} \%$ methylsuccinic acid, Marcolli et al., 2004), ammonium bisulfate (Aldrich, 99.999\%), sulfuric acid (Roth, rotipuran), 1:1 (per mass) raffinose/M5AS mixtures, 1:1 (per mass) 1,4-butanediol/1,2,7,8-octanetetrol mixtures and 1:1 (per mass) glucose/ammnoium nitrate mixtures. Within this study $\mathrm{C} 10$ is used as an abbreviation for 2,2,6,6Tetrakis(hydroxymethyl)cyclohexanol and HMMA for DL4-Hydroxy-3-methoxy mandelic acid.

A2 Experiments with aqueous organic, inorganic and multi-component solutions

The investigated aqueous solutions cover a maximum possible concentration range of the state diagram for each solute. For the more concentrated solutions a glass transition has been observed, whereas for more dilute samples homogeneous ice nucleation with subsequent ice melting has been detected. Tables A1 and A2 list the homogeneous ice freezing, ice melting and glass temperatures measured for the various aqueous organic, inorganic and multi-component solutions. Each listed temperature value is the average of one to three single experiments. In the case of homogeneous ice freezing or ice melting experiments the difference between consecutive measurements with the same emulsion was less than $0.2 \mathrm{~K}$. For independently prepared emulsions, freezing temperature deviations up to $1.0 \mathrm{~K}$ have been observed, indicating the high accuracy and reproducibility of the emulsion experiments.

The reproducibility for the ice melting temperatures in the emulsions and the glass temperatures in both sample types was even better: 9 glass temperatures of 3 identically prepared raffinose/M5AS bulk samples with a solute weight fraction of 0.765 showed a maximum deviation of $0.35 \mathrm{~K}$ and standard deviation of $0.1 \mathrm{~K}$. Considering also the tem- perature uncertainty due to the calibration leads to a maximum error in the temperature of $\pm 1.2 \mathrm{~K}, \pm 0.8 \mathrm{~K}, \pm 0.9 \mathrm{~K}$ for the homogeneous ice freezing, ice melting and glass temperatures, respectively. Since the glass temperature depends strongly on the solute concentration, an inaccuracy in the solution preparation of \pm 0.005 in weight fraction can lead to a maximum discrepancy of up to $5 \mathrm{~K}$ for a strongly concentrated raffinose solution. Nevertheless, the size of the symbols are typically larger than the experimental uncertainties in the temperatures and thus we omit temperature error bars in the figures.

A3 Gordon-Taylor parameterization for the glass temperatures of aqueous solutions

The measured glass temperatures were used to determine for each solute or multi-component solution a $k$ and a $T_{\mathrm{g} 2}$ value according to the Gordon-Taylor equation (see Eq. 1). Thus the glass transition temperature can be calculated over the entire concentration range. Table A3 lists the $k$ and $T_{\mathrm{g} 2}$ values for all the investigated systems.

$T_{\mathrm{g} 2}$ denotes the glass temperature of the pure solute, which can in principle also be determined directly by investigating the pure melt of the solute. The $k$ value mainly determines the shape of the glass curve. A high $T_{\mathrm{g} 2}$ temperature usually goes in hand with a high $k$ value, with some exceptions: $\mathrm{H}_{2} \mathrm{SO}_{4}$ exhibits a $k$ value of 4.33 but has only a $T_{\mathrm{g} 2}$ of $220.5 \mathrm{~K}$. Table A3 lists also the uncertainties on a one standard deviation level for both fit parameters.

Figure A1 shows the uncertainty of the Gordon-Taylor fit for five selected samples, including the ones with the largest $\sigma^{\prime} s$. The solid lines are the glass curves calculated with the $k$ and $T_{\mathrm{g} 2}$ given in Table A3. The dashed lines depict the confidence bands on the plus/minus one standard deviation level of the solid line. This means that the closer the dashed and the solid lines are, the better the Gordon-Taylor fit is constrained by experimental data points. In the case of the $\mathrm{C} 4$ 


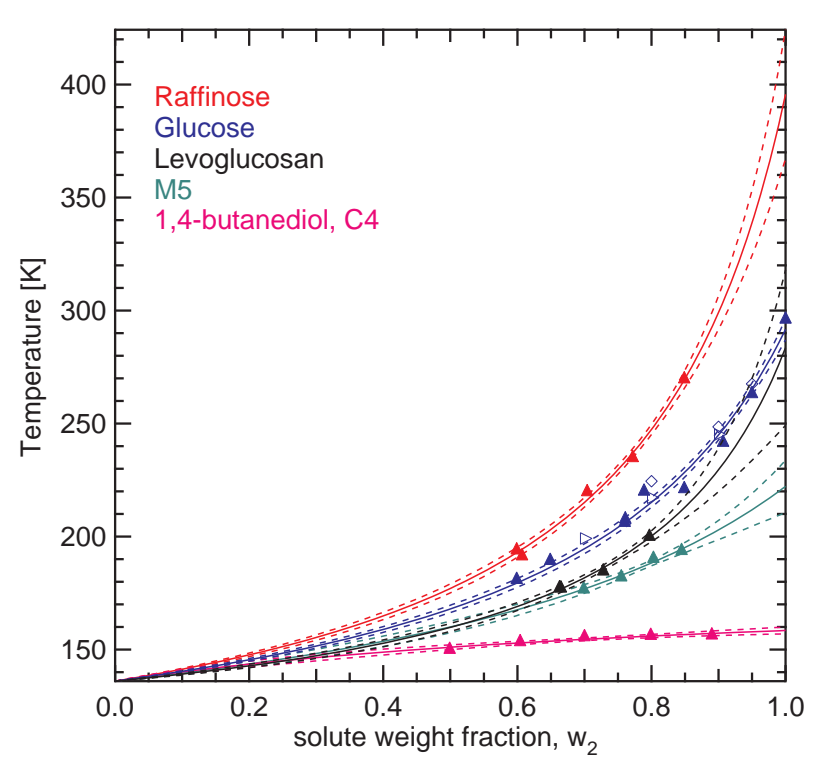

Fig. A1. Glass curves, solid lines, for five selected solutes as a function of the solute weight fraction. The symbols are the experimental data points given in Table A1. The solid lines are calculated with Eq. 1 and the dashed lines represent the uncertainty range on a one standard deviation level.

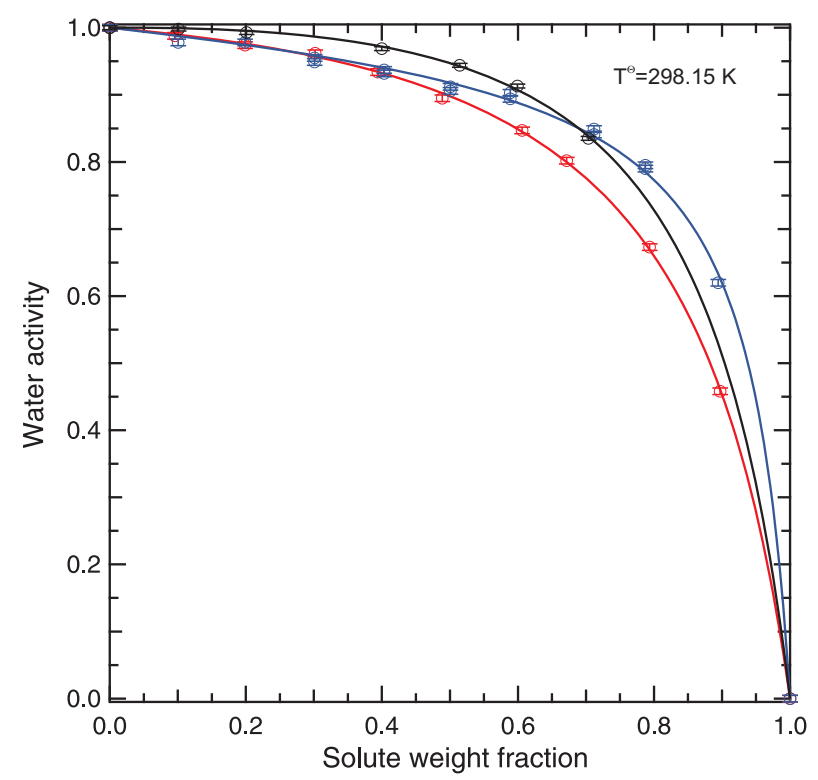

Fig. A2. Water activity of aqueous 1,2,6-hexanetriol (red), 2,5hexanediol (blue) and raffinose (black) solutions as a function of the solute weight fraction measured at $298.15 \mathrm{~K}$. Circles: measurements with error bars of $\pm 0.005 a_{\mathrm{W}}$ for the red and blue symbols and $\pm 0.003 a_{\mathrm{W}}$ for the black symbols. The solid curves are calculated according to Eq. A1.

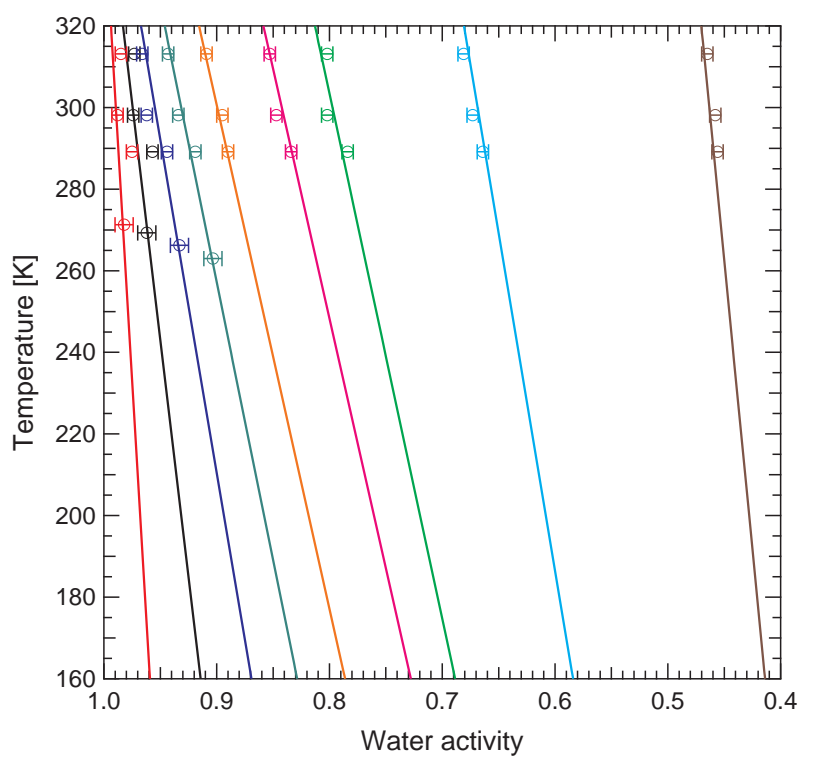

Fig. A3. Temperature dependent water activity for aqueous 1,2,6hexanetriol solutions. Circles: measurements with error bars. Lines: fitted curves according to Eq. A2 with different $w_{2}$ values. Red: 0.096, black: 0.199, blue: 0.302, dark green; 0.394, orange: 0.489 , magenta: 0.606 , light green: 0.672 , cyan: 0.794 and brown: 0.897 .

polyol, the dashed and the solid lines are almost congruent over the entire concentration range. The maximum difference between the two dashed lines is only $2.6 \mathrm{~K}$. The $\mathrm{C} 4$ polyol shows the lowest $\sigma$ values for both parameters. Raffinose, on the other hand, has one of the highest $\sigma_{\mathrm{k}}$ values and the highest $\sigma_{\mathrm{T}_{\mathrm{g} 2}}$. Nevertheless, the fit quality for raffinose is good as long as $w_{2}$ does not exceed the experimental concentration range. From the five samples shown in Fig.A1, one can conclude that the fit quality for all solutes is good in the investigated concentration range, but exhibits larger uncertainties at higher concentrations when experimental data could not be obtained due to the limited solubility of the solutes in water.

A4 $a_{\mathrm{w}}$ parameterization as a function of the temperature and the solute concentration

A proper description of the water activity as a function of the temperature and solute concentration is needed to convert the measured temperatures from a concentration into a water activity scale. Therefore, we measured the water activities of the investigated organic and multi-component solutions with an AquaLab dew point water activity meter (Model 3TE, Decagon devices, USA) in the temperature range from $289 \mathrm{~K}$ to $313 \mathrm{~K}$. The standard sample block of the AquaLab with a specified error of \pm 0.003 in $a_{\mathrm{w}}$ was used for most solutions. For the more volatile polyols (1,4-butanediol, 2,5-hexanediol, 1,2,6-hexanetriol and glycerol) the volatile 
sample block had to be used leading to an error of \pm 0.005 in $a_{\mathrm{w}}$. Each solution was measured at least three times at each temperature. Additional water activity data were derived from the $T_{\mathrm{m}}$ measurements if available and thus the investigated temperature range could be enlarged in maximum down to $252 \mathrm{~K}$.

The fit function for the temperature dependent $a_{\mathrm{w}}$ values was derived in two steps. First, the dependence of the solute concentration on the water activity was considered at a fixed temperature of $T^{\Theta}=298.15 \mathrm{~K}$. Figure A2 shows the measured $a_{\mathrm{w}}$ dependence for 1,2,6-hexanetriol, 2,5-hexanediol and raffinose solutions as a function of the weight fraction performed at $T^{\Theta}=298.15 \mathrm{~K}$. The data shows a strong decrease in $a_{\mathrm{w}}$ with increasing solute concentration. The data points were fitted according to:

$a_{\mathrm{w}}\left(w_{2}, T^{\Theta}\right)=\frac{\left(1+a \cdot w_{2}\right)}{\left(1+b \cdot w_{2}+c \cdot w_{2}^{2}\right)}$,

where $w_{2}$ is the solute weight fraction and $a, b$ and $c$ are fit parameters. There exists an excellent agreement between the measured $a_{\mathrm{w}}$ points and the fit function for all investigated systems.

In a second step, the dependence of the water activity on temperature was examined. The measured data indicate a linear dependence of $a_{\mathrm{w}}$ on temperature in the investigated temperature range, with the strongest temperature trends observed at medium concentrations, see also Fig. A3. The variation of the temperature dependence as a function of the concentration was approximated by a polynomial function, whereby the slopes at $a_{\mathrm{w}}$ of 0 and 1 were set to zero. Combining the linear temperature dependence with the concentration dependence yields Eq. A2, which expresses $a_{\mathrm{w}}$ as a function of the solute weight fraction $w_{2}$ and temperature:

$$
\begin{aligned}
& a_{\mathrm{w}}\left(w_{2}, T\right)=\frac{\left(1+a \cdot w_{2}\right)}{\left(1+b \cdot w_{2}+c \cdot w_{2}^{2}\right)} \\
& +\left(T-T^{\Theta}\right) \cdot\left(d \cdot w_{2}+e \cdot w_{2}^{2}+f \cdot w_{2}^{3}+g \cdot w_{2}^{4}\right),
\end{aligned}
$$

Where $T$ is the absolute temperature and $T^{\Theta}=298.15 \mathrm{~K}$ the standard temperature. The variables $a$ to $g$ are fit parameters and are listed for all investigated solutes in Table A4. Figure A3 shows the measured $a_{\mathrm{w}}$ as a function of temperature for aqueous 1,2,6-hexanetriol solutions. The colored lines are calculated according to Eq. (A2). There exists a good agreement with the measured data and the fitted curves confirm the fitting procedure. Assuming that the linear temperature trend of $a_{\mathrm{w}}$ can be extrapolated to temperature and concentration ranges that are not covered by measurements, Eq. (A2) was used within this study to determine the water activity in the temperature and concentration range of $160 \mathrm{~K}$ to $313 \mathrm{~K}$ and of 0 to 1 , respectively.
Acknowledgements. We are grateful for support by the European Commission through the integrated project SCOUT-O3 and by the Swiss National Fund in various projects. The authors thank Thomas Peter for fruitful discussions and help on the manuscript, Greta Stratmann for DSC and water activity measurements of the mixture M5, Birte Riechers for some water activity measurements and Xiaoming He for help to calculate the diffusion coefficients at low temperatures.

Edited by: V. F. McNeill

\section{References}

Ablett, S., Izzard, M. J., and Lillford, P. J.: Differential scanning calorimetric study of frozen sucrose and glycerol solutions, J. Chem. Soc. Faraday Trans., 88, 789-794, 1992.

Albrecht, B. A.: Aerosols, cloud microphysics and fractional cloudiness, Science, 245, 1227-1230, 1989.

Angell, C. A.: Formation of glasses from liquids and biopolymers, Science, 267, 1924-1935, 1995.

Angell, C. A.: Liquid fragility and the glass transition in water and aqueous solutions, Chem. Rev., 102, 2627-2649, 2002.

Angell, C. A.: Insights into phases of liquid water from study of its unusual glass-forming properties, Science, 319, 582-587, 2008.

Angell, C. A., Sare, E. J., Donnella, J., and MacFarlane, D. R.: Homogeneous nucleation and glass transition temperatures in solutions of Li salts in $\mathrm{D}_{2} \mathrm{O}$ and $\mathrm{H}_{2} \mathrm{O}$. Doubly unstable glass regions, J. Phys. Chem., 85, 1461-1464, 1981.

Atkins, P. W.: Physikalische Chemie, 188-189, VCH, Weinheim, 1996.

Baynard, T., Garland, R. M., Ravishankara, A. R., Tolbert, M. A., and Lovejoy, E. R.: Key factors influencing the relative humidity dependence of aerosol light scattering, Geophys. Res. Lett., 33 , L06813, doi:10.1029/2005GL024 898, 2006.

Blond, G., Simatos, D., Catté, M., Dussap, C. G., and Gros, J. B.: Modeling of the water-sucrose state diagram below $0^{\circ} \mathrm{C}$, Carbohydr. Res., 298, 139-145, 1997.

Carrico, C. M., Kus, P., Rood, M. J., Quinn, P. K., and Bates, T. S.: Mixtures of pollution, dust, sea salt, and volcanic aerosol during ACE-Asia: Radiative properties as a function of relative humidity, J. Geophys. Res., 108(D23), 8650, doi:10.1029/2003JD00340, 2003.

Clegg, S. L., Brimblecombe, P., and Wexler, A. S.: Thermodynamic model of the system $\mathrm{H}^{+}-\mathrm{NH}_{4}^{+}-\mathrm{SO}_{4}^{2-}-\mathrm{NO}_{3}^{-}-\mathrm{H}_{2} \mathrm{O}$ at tropospheric temperatures, J. Phys. Chem. A, 102, 2137-2154, 1998.

Colberg, C. A., Luo, B. P., Wernli, H., Koop, T., and Peter, T.: A novel model to predict the physical state of atmospheric $\mathrm{H}_{2} \mathrm{SO}_{4} / \mathrm{NH}_{3} / \mathrm{H}_{2} \mathrm{O}$ aerosol particles, Atmos. Chem. Phys., 3, 909-924, 2003.

Craig, D. Q. M., Royall, P. G., Kett, V. L., and Hopton, M. L.: The relevance of the amorphous state to pharmaceutical dosage forms: glassy drugs and freeze dried systems, Int. J. Pharm., 179, 179-207, 1999.

Cziczo, D. J., DeMott, P. J., Brooks, S. D., Prenni, A. J., Thomson, D. S., Baumgardner, D., Wilson, J. C., Kreidenweis, S. M., and Murphy, D. M.: Observations of organic species and atmospheric ice formation, Geophys. Res. Lett., 31, L12116, doi:10.1029/2004GL019822, 2004. 
Debenedetti, P. G.: Metastable liquids, 235-239, Princeton University Press, Princeton NJ, 1996.

Debenedetti, P. G. and Stillinger, F. H.: Supercooled liquids and the glass transition, Nature, 410, 259-267, 2001.

Decesari, S., Fuzzi, S., Facchini, M. C., Mircea, M., Emblico, L., Cavalli, F., Maenhaut, W., Chi, X., Schkolnik, G., Falkovich, A., Rudich, Y., Claeys, M., Pashynska, V., Vas, G., Kourtchev, I., Vermeylen, R., Hoffer, A., Andreae, M. O., Tagliavini, E., Moretti, F., and Artaxo, P.: Characterization of the organic composition of aerosols from Rondônia, Brazil, during the LBASMOCC 2002 experiment and its representation through model compounds, Atmos. Chem. Phys., 6, 375-402, 2006, http://www.atmos-chem-phys.net/6/375/2006/.

DeMott, P. J., Cziczo, D. J., Prenni, A. J., Murphy, D. M., Kreidenweis, S. M., Thomson, D. S., Borys, R., and Rogers, D. C.: Measurements of the concentration and composition of nuclei for cirrus formation, Proc. Natl. Acad. Sci., 100, 14 655-14660, 2003.

Denkenberger, K. A., Moffet, R. C., Holecek, J. C., Rebotier, T. P., and Prather, K. A.: Real-time, single-particle measurements of oligomers in aged ambient aerosol particles, Environ. Sci. Technol., 41, 5439-5446, 2007.

Ediger, M. D., Angell, C. A., and Nagel, S. R.: Supercooled liquids and glasses, J. Phys. Chem., 100, 13 200-13 212, 1996.

Ervens, B., Feingold, G., Frost, G. J., and Kreidenweis, S. M.: A modeling study of aqueous production of dicarboxylic acids: 1 . Chemical pathways and speciated organic mass production, J. Geophys. Res., 109, D15205, doi:10.1029/2003JD004387, 2004.

Fisseha, R., Dommen, J., Gaeggeler, K., Weingartner, E., Samburova, V., Kalberer, M., and Baltensperger, U.: Online gas and aerosol measurement of water soluble carboxylic acids in Zurich, J. Geophys. Res., 111, D12316, doi:10.1029/2005JD006782, 2006.

Folmer, J. C. W. and Franzen, S.: Study of polymer glasses by modulated differential scanning calorimetry in the undergraduate physical chemistry laboratory, J. Chem. Educ., 80, 813-818, 2003.

Fredenslund, A., Jones, R. L., and Prausnitz, J. M.: Groupcontribution estimation of activity-coefficients in nonideal liquid-mixtures, AIChE J., 21, 1086-1099, 1975.

Gable, C. M., Betz, H. F., and Maron, S. H.: Phase equilibria of the system sulfur trioxide-water, J. Am. Chem. Soc., 72, 1445-1448, 1950.

Gordon, M. and Taylor, J. S.: Ideal copolymers and the 2nd-order transitions of synthetic rubbers 1 . Non-crystalline copolymers, J. Appl. Chem., 2, 493-500, 1952.

Graham, B., Mayol-Bracero, O. L., Guyon, P., Roberts, G. C., Decesari, S., Facchini, M. C., Artaxo, P., Maenhaut, W., Köll, P., and Andreae, M. O.: Water-soluble organic compounds in biomass burning aerosols over Amazonia 1. Characterization by NMR and GC-MS, J. Geophys. Res., 107(D20), 8047, doi:10.1029/2001JD000336, 2002.

Hancock, B. C. and Zografi, G.: Characteristics and significance of the amorphous state in pharmaceutical systems, J. Pharm. Sci., 86, 1-12, 1997.

Hansen, J. E., Sato, M., Lacis, A., Ruedy, R., Tegen, I., and Matthews, E.: Climate forcings in the Industrial Era, Proc. Natl. Acad. Sci., 95, 12 753-12 758, 1998.

Haywood, J. and Boucher, O.: Estimates of the direct and indirect radiative forcing due to tropospheric aerosols: A review, Rev. Geophys., 38, 513-543, 2000.

He, X., Fowler, A., and Toner, M.: Water activity and mobility in solutions of glycerol and small molecular weight sugars: Implication for cryo- and lyopreservation, J. Appl. Phys., 100, 074702; doi:10.1063/1.2434975, 2006.

IPCC(2007), Solomon, S., Qin, D., Manning, M., Chen, Z., Marquis, M., Averyt, K. B., Tignor, M., and Miller, H. L.: Climate Change 2007: The physical science basis. Contribution of working group I to the Fourth Assessment Report of the Intergovernmental Panel on Climate Change, Cambridge University Press, Cambridge, United Kingdom and New York, NY, USA, 2007.

Jensen, E. J., Smith, J. B., Pfister, L., Pittman, J. V., Weinstock, E. M., Sayres, D. S., Herman, R. L., Troy, R. F., Rosenlof, K., Thompson, T. L., Fridlind, A. M., Hudson, P. K., Cziczo, D. J., Heymsfield, A. J., Schmitt, C., and Wilson, J. C.: Ice supersaturations exceeding $100 \%$ at the cold tropical tropopause: implications for cirrus formation and dehydration, Atmos. Chem. Phys., 5, 851-862, 2005.

Johari, G. P., Hallbrucker, A., and Mayer, E.: The glass-liquid transition of hyperquenched water, Nature, 330, 552-553, 1987.

Kalberer, M., Paulsen, D., Sax, M., Steinbacher, M., Dommen, J., Prevot, A. S. H., Fisseha, R., Weingartner, E., Frankevich, V., Zenobi, R., and Baltensperger, U.: Identification of polymers as major components of atmospheric organic aerosols, Science, 303, 1659-1662, 2004.

Kanakidou, M., Seinfeld, J. H., Pandis, S. N., Barnes, I., Dentener, F. J., Facchini, M. C., Van Dingenen, R., Ervens, B., Nenes, A., Nielsen, C. J., Swietlicki, E., Putaud, J. P., Balkanski, Y., Fuzzi, S., Horth, J., Moortgat, G. K., Winterhalter, R., Myhre, C. E. L., Tsigaridis, K., Vignati, E., Stephanou, E. G., and Wilson, J.: Organic aerosol and global climate modelling: a review, Atmos. Chem. Phys., 5, 1053-1123, 2005.

Kanno, H. and Itoi, H.: Glass formation study of sulphuric acid (in Japanese), Ryusan to Kogyo, 37, 181-187, 1984.

Kärcher, B. and Koop, T.: The role of organic aerosols in homogeneous ice formation, Atmos. Chem. Phys., 5, 703-714, 2005.

Katkov, I. I. and Levine, F.: Prediction of the glass transition temperature of water solutions: comparison of different models, Cryobiology, 49, 62-82, 2004.

Kawamura, K. and Ikushima, K.: Seasonal changes in the distribution of dicarboxylic acids in the urban atmosphere, Environ. Sci. Technol., 27, 2227-2235, 1993.

Kawamura, K., Seméré, R., Imai, Y., Fujii, Y., and Hayashi, M.: Water soluble dicarboxylic acids and related compounds in Antarctic aerosols, J. Geophys. Res., 101(D13), 18 721-18 728, 1996a.

Kawamura, K., Kasukabe, H., and Barrie, L. A.: Source and reaction pathways of dicarboxylic acids, ketoacids and dicarbonyls in Arctic aerosols: One year of observations, Atmos. Env., 30, 1709-1722, 1996b.

Kerč, J. and Srčič, S.: Thermal analysis of glassy pharmaceuticals, Thermochimica Acta, 248, 81-95, 1995.

Kilmartin, P. A., Reid, D. S., and Samson, I.: The measurement of the glass transition temperature of sucrose and maltose solutions with added NaCl, J. Sci. Food Agric., 80, 2196-2202, 2000.

Kiss, G., Tombácz, E., Varga, B., Alsberg, T., and Persson, L.: Estimation of the average molecular weight of humic-like substances isolated from fine atmospheric aerosol, Atmos. Env., 37, 3783- 
3794, 2003.

Kohl, I., Bachmann, L., Hallbrucker, A., Mayer, E., and Loerting, T.: Liquid-like relaxation in hyperquenched water at $\leq 140 \mathrm{~K}$, Phys. Chem. Chem. Phys., 7, 3210-3220, 2005.

Koleske, J. V. and Lundberg, R. D.: Lactone polymers. I. Glass transition temperature of poly-epsilon-caprolactone by means of compatible polymer mixtures, J. Polym. Sci. A, 7, 795-807, 1969.

Koop, T.: The water activity of aqueous solutions in equilibrium with ice, Bull. Chem. Soc. Jpn., 75, 2587-2588, 2002.

Koop, T., Luo, B. P., Tsias, A., and Peter, T.: Water activity as the determinant for homogeneous ice nucleation in aqueous solutions, Nature, 406, 611-614, 2000.

Krivácsy, Z., Gelencsér, A., Kiss, G., Mészáros, E., Molnár, A., Hoffer, A., Mészáros, T., Sárvári, Z., Temesi, D., Varga, B., Baltensperger, U., Nyeki, S., and Weingartner, E.: Study on the chemical character of water soluble organic compounds in fine atmospheric aerosol at the Jungfraujoch, J. Atmos. Chem., 39, 235-259, 2001

Krivácsy, Z., Kiss, G., Ceburnis, D., Jennings, G., Maenhaut, W., Salma, I., and Shooter, D.: Study of water-soluble atmospheric humic matter in urban and marine environments, Atmos. Res., 87, 1-12, 2008.

Langer, R. and Vacanti, J. P.: Tissue engineering, Science, 260, 920-926, 1993.

Lawson, R. P., Pilson, B., Baker, B., Mo, Q., Jensen, E., Pfister, L., and Bui, P.: Aircraft measurement of microphysical properties of subvisible cirrus in the tropical tropopause layer, Atmos. Chem. Phys., 8, 1609-1620, 2008.

Lerici, C. R., Piva, M., and Rosa, M. D.: Water activity and freezing point depression of aqueous solutions and liquid foods, J. Food Sci., 48, 1667-1669, 1983.

Levine, H. and Slade, L.: A polymer physico-chemical approach to the study of commercial Starch Hydrolysis Products (SHPs), Carbohydr. Polym., 6, 213-244, 1986.

Lohmann, U. and Feichter, J.: Global indirect aerosol effects: a review, Atmos. Chem. Phys., 5, 715-737, 2005.

Luyet, B. and Rasmussen, D.: Study by differential thermal analysis of the temperatures of instability of rapidly cooled solutions of glycerol, ethylene glycol, sucrose and glucose, Biodynamica, 10, 167-191, 1968.

Maltini, E., Anese, M., and Shtylla, I.: State diagrams of some organic acid-water systems of interest in food, Cryoletters, 18, 263-268, 1997.

Marcolli, C., Luo, B. P., and Peter, T.: Mixing of the organic aerosol fractions: Liquids as the thermodynamically stable phases, J. Phys. Chem. A, 108, 2216-2224, 2004.

Martin, S. T.: Phase transitions of aqueous atmospheric particles, Chem. Rev., 100, 3403-3453, 2000.

Middlebrook, A. M., Murphy, D. M., and Thomson, D. S.: Observations of organic material in individual marine particles at Cape Grim during the First Aerosol Characterization Experiment (ACE 1), J. Geophys. Res., 103, 16475-16483, 1998.

Miyata, K. and Kanno, H.: Supercooling behavior of aqueous solutions of alcohols and saccharides, J. Mol. Liquids, 119, 189-193, 2005.

Möhler, O., Linke, C., Saathoff, H., Schnaiter, M., Wagner, R., Mangold, A., Krämer, M., and Schurath, U.: Ice nucleation on flame soot aerosol of different organic carbon content, Meteorol.
Z., 48, 477-484, 2005.

Murphy, D. M., Cziczo, D. J., Froyd, K. D., Hudson, P. K., Matthew, B. M., Middlebrook, A. M., Peltier, R. E., Sullivan, A., Thomson, D. S., and Weber, R. J.: Single-particle mass spectrometry of tropospheric aerosol particles, J. Geophys. Res., 111, D23S32, doi:10.1029/2006JD007340, 2006.

Murray, B. J.: Inhibition of ice crystallisation in highly viscous aqueous organic acid droplets, Atmos. Chem. Phys. Discuss., 8, 8743-8771, 2008a.

Murray, B. J.: Enhanced formation of cubic ice in aqueous organic acid droplets, Environ. Res. Lett., 3, 025008, doi:10.1088/17489326/3/2/025008, 2008b.

Narukawa, M., Kawamura, K., Okada, K., Zaizen, Y., and Makino, Y.: Aircraft measurements of dicarboxylic acids in the free tropospheric aerosols over the western to central North Pacific, Tellus, 55B, 777-786, 2003.

Novakov, T., Hegg, D. A., and Hobbs, P. V.: Airborne measurements of carbonaceous aerosols on the East Coast of the United States, J. Geophys. Res., 102(D25), 30 023-30 030, 1997.

Pegg, D. E. and Karow, A. M. E.: The biophysics of organ cryopreservation, 147-171, Plenum Pres, New York, 1987.

Peter, T., Marcolli, C., Spichtinger, P., Corti, T., Baker, M. B., and Koop, T.: When dry air is too humid, Science, 314, 1399-1402, 2006.

Quinn, P. K., Bates, T. S., Baynard, T., Clarke, A. D., Onasch, T. B., Wang, W., Rood, M. J., Andrews, E., Allan, J., Carrico, C. M., Coffman, D., and Worsnop, D.: Impact of particulate organic matter on the relative humidity dependence of light scattering: A simplified parameterization, Geophys. Res. Lett., 32, L22809, doi:10.1029/2005GL024322, 2005.

Rampp, M., Buttersack, C., and Lüdemann, H. D.: c,T-dependence of the viscosity and the self-diffusion coefficients in some aqueous carbohydrate solutions, Carbohydr. Res., 328, 561-572, 2000.

Rasmussen, D. H. and MacKenzie, A. P.: Effect of solute on icesolution interfacial free energy; calculation from measured homogeneous nucleation temperatures, in: Water structure at the water polymer interface, edited by Jellinek, H. H. G., pp. 126145, Plenum Press, New York, 1972.

Rogge, W. F., Mazurek, M. A., Hildemann, L. M., Cass, G. R., and Simoneit, B. R. T.: Quantification of urban organic aerosols at a molecular level: Identification, abundance and seasonal variation, Atmos. Env., 27A, 1309-1330, 1993.

Roos, Y. H.: Melting and glass transitions of low molecular weight carbohydrates, Carbohydr. Res., 238, 39-48, 1993.

Satoh, K. and Kanno, H.: Anomalous crystallization behavior in the glass forming composition region of the $\mathrm{H}_{2} \mathrm{O}-\mathrm{HNO}_{3}$-system, Bull. Chem. Soc. Jpn., 55, 1645-1646, 1982.

Saxena, P. and Hildemann, L. M.: Water-soluble organics in atmospheric particles: A critical review of the literature and application of thermodynamics to identify candidate compounds, J. Atmos. Chem., 24, 57-109, 1996.

Seo, J. A., Kim, S. J., Oh, J., Kim, H. K., Hwang, Y. H., and Yang, Y. S.: Brillouin scattering and DSC studies of glass transition temperatures of glucose-water mixtures, J. Korean Phys. Soc., 44, 523-526, 2004.

Shalaev, E. Y., Franks, F., and Echlin, P.: Crystalline and amorphous phases in the ternary system water-sucrose-sodium chloride, J. Phys. Chem., 100, 1144-1152, 1996. 
Slade, L. and Levine, H.: Water and the glass transition - Dependence of the glass transition on composition and chemical structure: Special implications for flour functionality in cookie baking, J. Food Eng., 22, 143-188, 1994.

Stokes, R. H. and Robinson, R. A.: Interactions in aqueous nonelectrolyte solutions I. Solute-solvent equilibria, J. Phys. Chem., 70, 2126-2131, 1966.
Young, F. E.: D-glucose-water phase diagram, J. Phys. Chem., 61, 616-619, 1957.

Zahardis, J. and Petrucci, G. A.: The oleic acid-ozone heterogeneous reaction system: products, kinetics, secondary chemistry, and atmospheric implications of a model system - a review, Atmos. Chem. Phys., 7, 1237-1274, 2007,

http://www.atmos-chem-phys.net/7/1237/2007/. 